\section{Pacific Northwest} National Laboratory

Operated by Battelle for the

U.S. Department of Energy

\title{
Air Quality and Road Emission Results for Fort Stewart, Georgia
}

\author{
R. R. Kirkham \\ M. A. Chamness \\ C. J. Driver \\ B. C. Barfuss
}

February 2005

\author{
Prepared for the U.S. Department of Energy \\ under Contract DE-AC05-76RL01830
}




\title{
DISCLAIMER
}

This report was prepared as an account of work sponsored by an agency of the United States Government. Neither the United States Government nor any agency thereof, nor Battelle Memorial Institute, nor any of their employees, makeany warranty, express or implied, or assumes any legal liability or responsibility for the accuracy, completeness, or usefulness of any information, apparatus, product, or process disclosed, or represents that its use would not infringe privately owned rights. Reference herein to any specific commercial product, process, or service by trade name, trademark, manufacturer, or otherwise does not necessarily constitute or imply its endorsement, recommendation, or favoring by the United States Government or any agency theref, or Battelle Memorial Institute. The views and opinions of authors expressed herein do not necessarily state or reflect those of the United States Government or any agency thereof.

\author{
PACIFIC NORTHWEST NATIONAL LABORATORY \\ operated by \\ BATTELLE \\ for the \\ UNITED STATES DEPARTMENT OF ENERGY \\ under Contract DE-AC05-76RL01830
}

Printed in the United States of America
Available to DOE and DOE contractors from the Office of Scientific and Technical Information,
P.O. Box 62, Oak Ridge, TN 37831-0062;
ph: (865) 576-8401
fax: (865) 576-5728
email: reports@adonis.osti.gov

\footnotetext{
Available to the public from the National Technical Information Service, U.S. Department of Commerce, 5285 Port Royal Rd., Springfield, VA 22161 ph: (800) 553-6847 fax: (703) 605-6900 email: orders@ntis.fedworld.gov online ordering: http://www.ntis.gov/ordering.htm
}

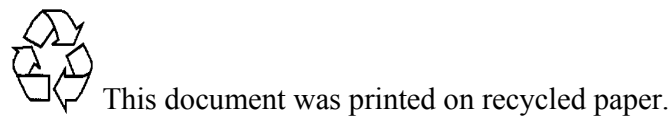




\section{Air Quality and Road Emission Results for Fort Stewart, Georgia}
R. R. Kirkham
M. A. Chamness
C. J. Driver
B. C. Barfuss

February 2005

Prepared for

the Directorate of Public Works

Environmental and Natural Resources Division,

Fort Stewart/Hunter Army Airfield

under a Related Services Agreement

with the U.S. Department of Energy

Contract DE-AC05-76RL01830

Pacific Northwest National Laboratory

Richland, Washington 99352 


\section{Summary}

The Directorate of Public Works Environmental \& Natural Resources Division (Fort Stewart/Hunter Army Airfield) contracted with the Pacific Northwest National Laboratory (PNNL) to monitor particulate matter (PM) concentrations at Fort Stewart, Georgia. The purpose of this investigation was to establish a PM sampling network using monitoring equipment typically used in U.S. Environmental Protection Agency (EPA) "saturation sampling," which is generally a receptor-based approach to sampling where receptors (humans) are likely to be present within an urban environment.

In this initial study, the emphasis was on training-generated PM, not receptor PM loading. The majority of PM samples were 24-hour filter-based samples with sampling frequency ranging from every other day, to once every six days synchronized with the EPA $6^{\text {th }}$ day national sampling schedule. Eight measurement sites were established and used to determine spatial variability in PM concentrations and evaluate whether fluctuations in PM appear to result from training activities and forest management practices on the installation.

Data collected to date indicate the average installation PM2.5 concentration is lower than that of nearby urban Savannah, Georgia. At three sites near the installation perimeter, analyses to segregate PM concentrations by direction of air flow across the installation boundary indicate that air (below $80 \mathrm{ft}$ ) leaving the installation contains less PM2.5 than that entering the installation. This is reinforced by the observation that air near the ground is cleaner on average than the air at the top of the canopy. 


\section{Acknowledgments}

The authors extend their appreciation to Tressa Rutland with DPW-ENRD Environmental Branch at Fort Stewart, Jackie Dubose for document review and for arranging access and UXO training, and Monica Moncrief and fire tower staff of the Forestry Div-DPW for allowing access to the fire towers and supplying meteorological and prescribed burn information. We also would like to thank Dan Gary of the Georgia Forestry Commission for supplying off installation burn data, Andy Burke for his help in field data collection, and Rochelle Williams (formerly with U.S. Army Forces Command) for her efforts in establishing a multi-installation PM monitoring program and insightful comments on PM relationships to installation operation and training. 


\section{Contents}

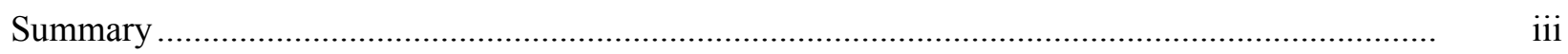

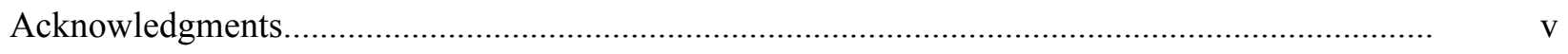

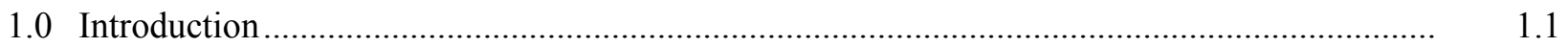

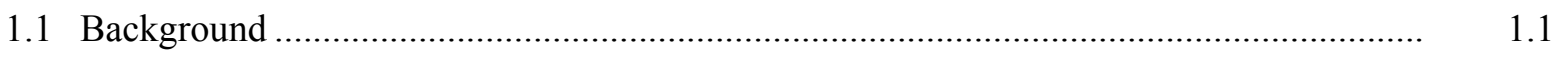

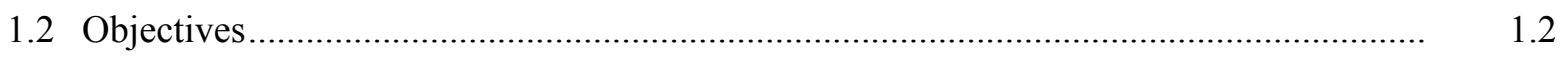

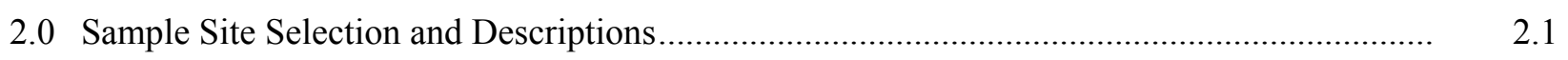

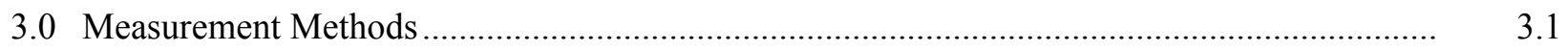

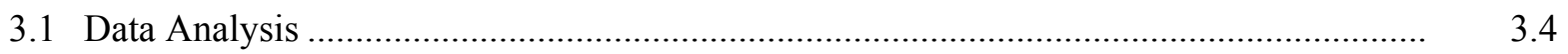

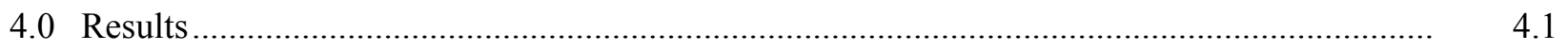

4.1 Comparison of Fort Stewart and Savannah PM ........................................................

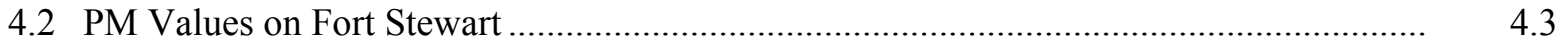

4.3 Transport of PM Across Installation Boundary ............................................................

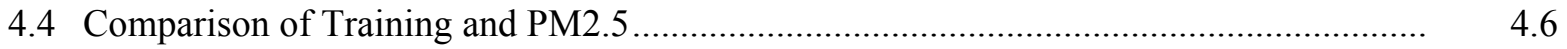

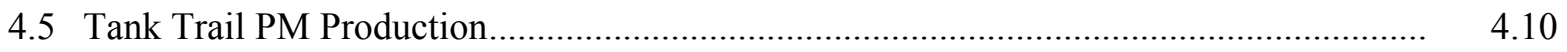

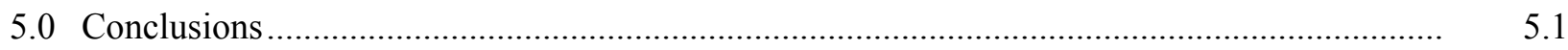

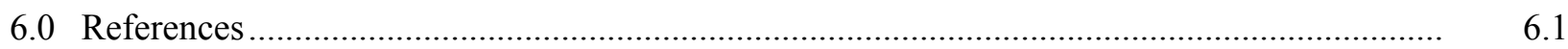

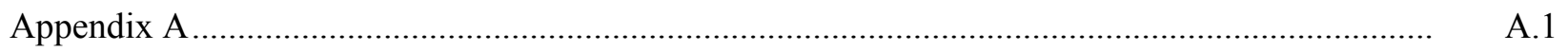




\section{Figures}

1.1 Fort Stewart and Particulate Matter Sample Site Locations with Surrounding Population Density

2.1 Spatial Areas Most Likely to Contribute Air Flow to Fort Stewart

2.2 Fort Stewart Elevation and Aerial Detail of Each Air Sampling Site

2.3 Aerial View of Glisson Site with 500-Mile Reference Circle.

3.1 Typical Fire Tower with Staff Working at Upper Sampler Height.

3.2 Job Site Box Containing MinVol and Tubing Running to Inlet Heads.

3.3 Tree Site with 25-Foot Pole Used to Hold PM Inlets.

3.4 Mobile Dust Mapper Uses Nepholometers to Measure the UVPM Produced Behind the Front Wheel.

4.1 PM2.5 Values for Eight Measurement Sites and Two Heights.

4.2 Richmond PM2.5 Concentrations Compared to Wind Direction.

4.3 Pembroke PM Values and Wind Direction

4.4 West Site PM2.5 Concentrations Compared to the Wind Direction.....

4.5 Scatter Plot Relating PM2.5 Concentration to Troop Number and Days Since Rain

4.6 Troop Levels and Prescribed Burns on January 28, 2001

4.7 Troop Levels and Prescribed Burns on January 29, 2001

4.8 Smoke Plume Originating in the Okefenokee Swamp Passing Over the Fort Stewart Sampling Sites on May 8, 2002

4.9 Relative PM10 Production from Tank Trails Between June 28 and July 1, 2002

4.10 May 2000 and July 2002 PM Sampling with MDM 


\section{Tables}

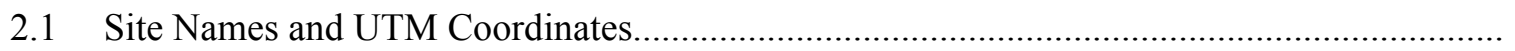

4.1 Data Available for Comparison of Fort Stewart Sequential Sampler and Two Savannah PM2.5 Sites July 2000-October 2002 . 


\subsection{Introduction}

Fort Stewart, Georgia, is home of the 3d infantry Division (Mechanized) and is the largest Army installation east of the Mississippi River. As part of ongoing environmental monitoring efforts at Fort Stewart, information is needed on the levels of suspended particulate matter (PM) found on and potentially leaving the installation. Exposure to excessive concentrations of these inhalable fractions of PM has been implicated in adverse public health effects (USEPA 1996; Vedal 1997). Pacific Northwest National Laboratory (PNNL) under contract to the Directorate of Public Works (DPW) Environmental \& Natural Resources Division (Fort Stewart/Hunter Army Airfield) initiated a study to evaluate airborne concentrations of particulates less than $10 \mu \mathrm{m}$ (PM10) and $2.5 \mu \mathrm{m}$ (PM2.5) with respect to conditions and training activities on the installation. In 1999, PNNL established a sampling network at Fort Stewart; sampling was conducted through 2002. This report presents the initial results of that study.

\subsection{Background}

Fort Stewart, located in eastern Georgia, encompasses approximately 280,000 acres of mostly pine forest. It stretches 39 miles from east to west and 19 miles from north to south. The installation is primarily forested with a few large grass-covered areas associated with firing ranges. The installation contains an extensive network of dirt and concrete paved roads commonly referred to as tank trails. Tracked and heavy tactical vehicles use this tank trail network to travel from the cantonment area to various training areas located throughout the installation. Prescribed burns are a major activity in the pine forest ecosystem. The prescribed burns are used to promote red-cockaded woodpecker habitat, Army training, and forest productivity. Many of the forest stands surrounding installation boundaries are also treated by prescribed burning.

The installation is surrounded by agricultural fields with typical crops, including tobacco, cotton, vegetables and poultry production. Nearby urban development is concentrated in the towns of Hinesville (contiguous with the Fort Stewart cantonment area at the south end of the installation); Pembroke, located approximately 2 miles north of the installation boundary; Richmond Hill, located 2 miles east; and Glennville, located 2 miles from the western boundary. The large urban area associated with the city of Savannah is located approximately 20 miles to the east. The installation extent and surrounding population density is shown in Figure 1.1.

The Savannah metropolitan area represents the nearest area with historical PM monitoring. PM10 data have been collected in Savannah by the Georgia Department of Natural Resources (GADNR) since May 1996. The air quality web site maintained by the GADNR reports that daily and yearly averages for PM10 did not exceed the regulatory limits of $150 \mu \mathrm{g} / \mathrm{m}^{3}$ per day or $50 \mu \mathrm{g} / \mathrm{m}^{3}$ per year since measurements began in 1996. Therefore, the Savannah metropolitan area is in attainment with respect to the PM10 standard. However, new National Ambient Air Quality Standards (NAAQS) regulations for PM2.5 are likely to be more difficult for the region to meet; therefore, this investigation has emphasized measurements for particles in the fine particle (PM2.5) size fraction. 


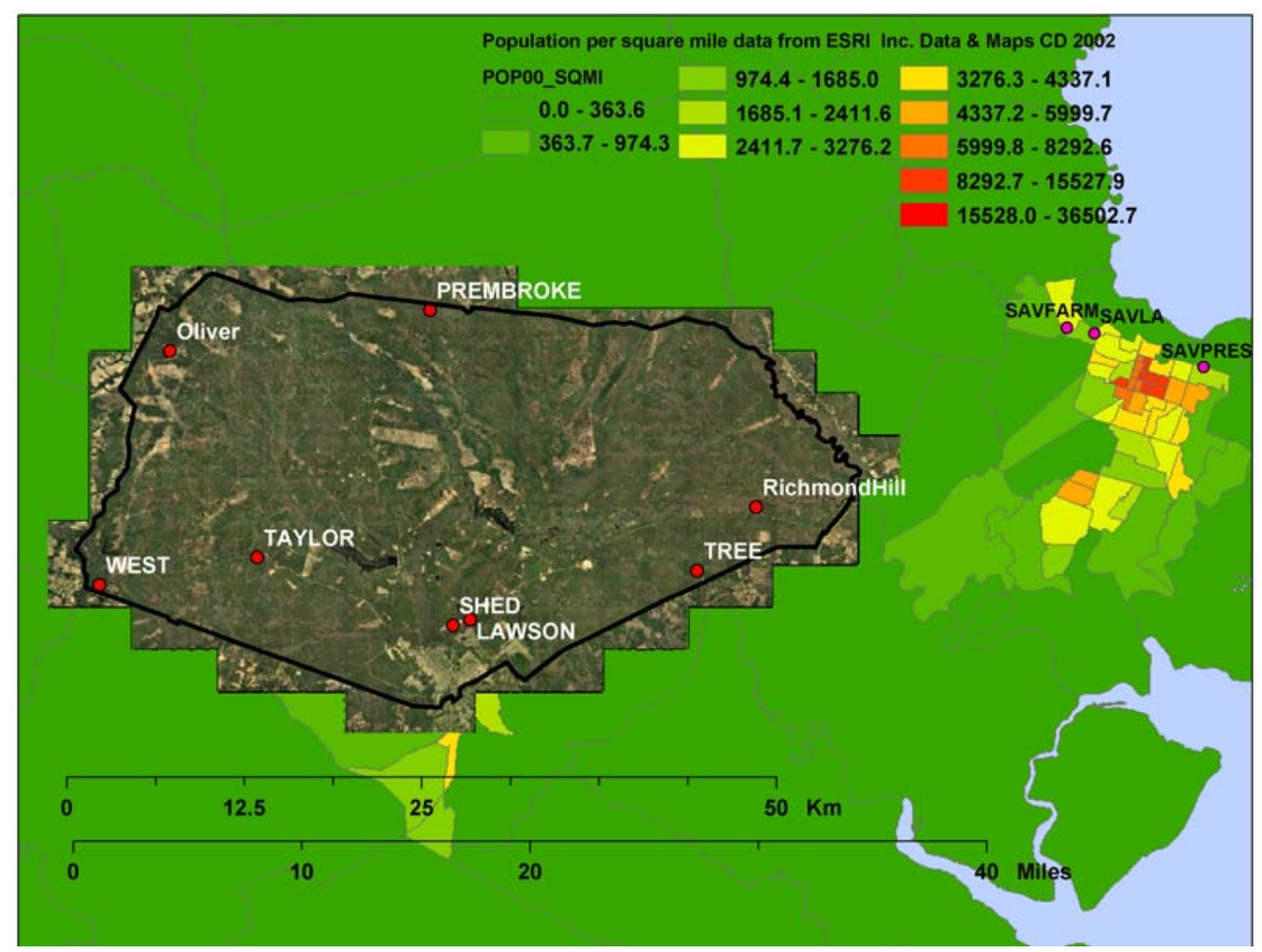

Figure 1.1. Fort Stewart and Particulate Matter Sample Site Locations with Surrounding Population Density (SALVA, SAVFARM, and SAVPRES are Georgia Department of Natural Resources air sampling sites)

\subsection{Objectives}

U.S. Army Forces Command (FORSCOM) has been active in establishing program air managers at many of the larger Army facilities. The air manager is responsible for obtaining permits and meeting state and federal air quality regulations. Previous efforts of the Fort Stewart air program have been directed at permitting and regulatory compliance issues.

In 1999, a field-measurement program to determine the effects of large-scale training on air quality within the borders of Fort Stewart was initiated. This was partially driven by the proposed PM2.5 regulations that were expected to list much of the East Coast as being in non-attainment status and by the lack of PM measurements within the installation boundary, necessary for determining how the installation air quality compared to nearby Savannah.

PNNL's first objective was to establish a field air measurement program to determine PM10 and PM2.5 concentrations at selected areas of the installation near training areas. The PM data can also be compared with the nearby Savannah air sampling sites to determine if installation air quality differs from the nearby urban area. At Fort Stewart, complicating factors in establishing a measurement program included the large spatial extent, extensive and tall vegetative cover (pine trees $80+\mathrm{ft}$ ), the potential for 
significant nighttime emissions (much of the military training occurs at night resulting in particulate sources whose locations are unknown and rapidly changing), and prescribed burns within and outside of the installation.

Visual observations during site visits and experience from other Army installations indicate unpaved roadways and tank trails are associated with most training-related PM production. A second objective of the field task was to identify roadway sections with the greatest production of PM. Mapping relative roadway contributions of PM allows managers to target problematic road sections and enhance the effectiveness of stabilizer applications (a limited resource). A subset (heavily used) of tank trails were characterized by measuring relative PM emissions underneath a four-wheel vehicle driving on the tank trails at $20 \mathrm{mph}$. This information will be useful to determine if soil type information from a soils map can be used to indicate which trails will contribute the most PM. The spatial information on relative roadway emission will help identify which specific segments of tank trails sampled contribute the most to PM releases. 


\subsection{Sample Site Selection and Descriptions}

Because PM related to training can be produced anywhere within the boundary of Fort Stewart, we considered the entire installation as the study site. The ocean is only a few miles east of the installation, but the I-95 freeway runs between the ocean and the installation, and it is bordered by typical strip commercial buildup. The metropolitan Savannah area also is east of the installation. Locations of sampling sites were determined after consideration of several factors, including proximity to the installation boundary, location of facilities, and meteorology.

The approach recommended by the U.S. Environmental Protection Agency (EPA) when first assessing the PM concentration in an airshed or large facility is to saturate the area with samplers. Often, this is referred to as "saturation sampling." A facility is usually easy to define either as building walls or property boundary. Airshed boundaries are usually defined by geographic features, such as mountains that block or divert flow. The Fort Stewart airshed is not well defined as the elevation gradually increases from sea level at the Atlantic Ocean to a few hundred feet many miles west of the installation.

General flow patterns can help determine regional scale areas that are more likely to contribute to installation air quality or be affected by PM production on the installation. Initial examination of local weather data did not indicate a strong dominant prevalent air flow pattern; therefore, wind direction was not considered during sample site selection. The lack of a dominant flow pattern was also observed in recent model simulations using actual wind data for 2001. Model simulations of back trajectories for each day of 2001 were generated using the Hybrid Single-Particle Lagrangian Integrated Trajectory model (HYSPLIT, a particle transport model; Draxler 1999). The model simulation started at a location near the center of the installation and generated a position representing where the air parcel was previously each hour up to 24 hours before noon. A density plot at 1-km grid scale was generated from each day's back trajectory to show the areas that were more likely to contribute an air parcel to the Fort Stewart airshed. The density plot in Figure 2.1 is remarkably uniform with only slightly increased likelihood of air entering the installation from the west and from the northeast (Savannah).

The presence of tall dense pine forest complicated selection of appropriate sample sites, because the environment existing beneath a closed canopy (i.e., relative humidity, wind speed, and wind direction) can be quite different from that found above the canopy. Surface air mixes with upper elevations by an exchange of air parcels referred to as eddies. Eddy size increases with height, and in an open, obstruction-free environment, the process of mixing is primarily controlled by thermal (buoyancy) and shear (wind speed) processes that affect eddy size and movement. This mixing process can be greatly reduced by introduction of a physical barrier such as a vegetation canopy. The dense canopy reduces

mixing between local source/receptor at ground level and air above the forest canopy where larger scale transport would dominate. Additionally, the trees act as a source (pollen) or sink (interception of dust by leaves) for PM. 


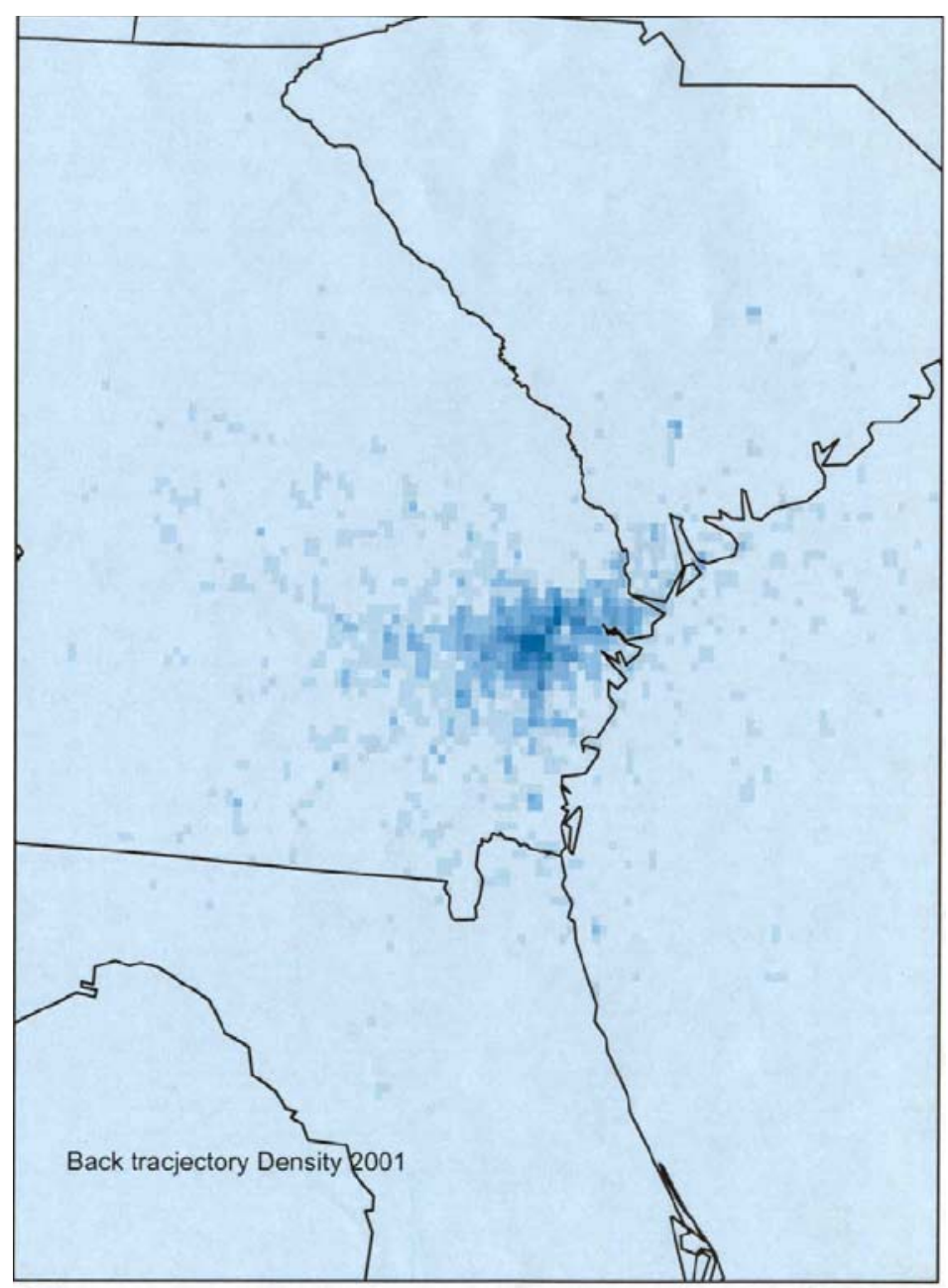

Figure 2.1. Spatial Areas Most Likely to Contribute Air Flow to Fort Stewart

As a result, for this study we used a dual-height sampling design to examine if the tall canopy was a significant factor in PM concentrations. The existing fire tower network (five sites) was selected as readily available sites where sampling could be accomplished near the top of the canopy. Samplers were located $80 \mathrm{ft}$ above ground level on each tower. The lower sampler was located approximately $7 \mathrm{ft}$ above ground level, to sample near-field source concentrations. The above-ground height of the lower sampler is similar to most receptor studies where the PM exposure of humans is being measured.

The tower sites are referred to as Lawson, Taylor, Oliver (or Glisson), Pembroke, and Richmond Hill as shown in Figure 2.2. Two additional sites in recently logged tracts were established on the western and southeastern installation boundaries, respectively referred to as West and Tree. A centrally located base of operations was established approximately 1 mile north of the cantonment area along highway 144, and is referred to as Shed or Central site (CS). The Shed site has phone capabilities, power and storage facilities, and positions the PM samplers approximately $300 \mathrm{ft}$ north of the state highway. Coordinates (UTM WGS84 zone 17) for each site are listed in Table 2.1. 


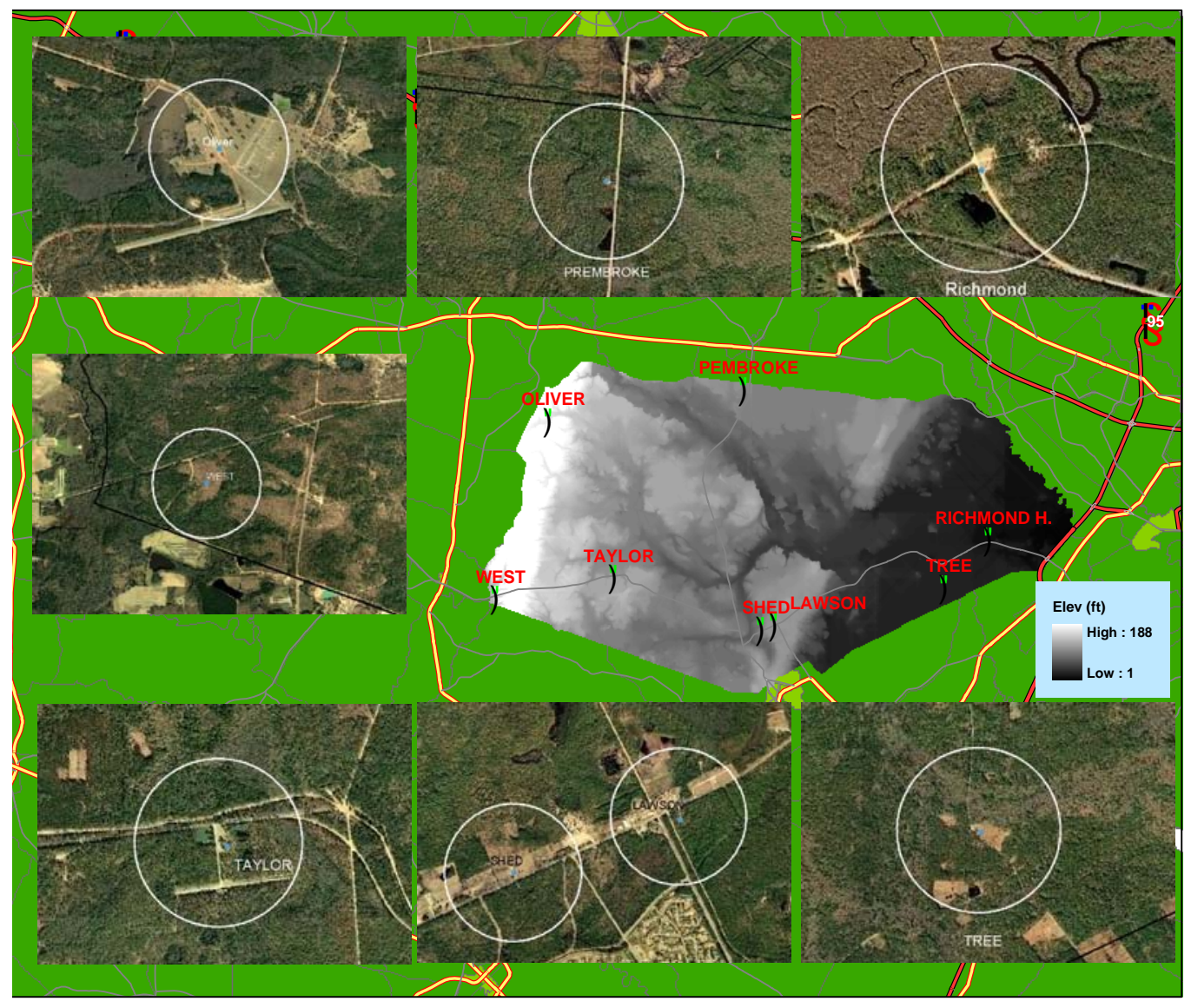

Figure 2.2. Fort Stewart Elevation (grey scale) and Aerial Detail of Each Air Sampling Site

Table 2.1. Site Names and UTM Coordinates

\begin{tabular}{||l|c|c||}
\hline \multicolumn{1}{|c|}{ Site } & Easting & $\begin{array}{c}\text { Northing } \\
\text { (zone 17, wgs84) }\end{array}$ \\
\hline \hline Tree & 459716 & 3533489 \\
\hline Lawson & 443740 & 3529991 \\
\hline Shed & 442526 & 3529605 \\
\hline Taylor & 428749 & 3534422 \\
\hline West & 417652 & 3532489 \\
\hline Prembroke & 440927 & 3551897 \\
\hline Oliver (Glisson's Pond) & 422609 & 3549023 \\
\hline Richmond & 463879 & 3537966 \\
\hline SAVLA (GA DNR site) & 487680 & 3550262 \\
\hline SAVFARM (GA DNR site) & 485741 & 3550665 \\
\hline SAVPRES (GA DNR site) & 495375 & 3547850 \\
\hline
\end{tabular}


Aerial images with a 1,640-ft $(500-\mathrm{m})$ radius for scale encircling the tower or pole sampling site are shown in Figure 2.2 for West, Pembroke, Taylor, Lawson, Tree, and Richmond Hill. Of the five tower sites, Oliver has the least expanse of tall canopy with Camp Oliver to the east, buildings to the west, and Glisson's Pond to the north, shown in Figure 2.3. Pembroke is approximately 1,600 ft from the northern installation boundary and is surrounded by 100 -ft-tall pine trees. Lawson is near the northern end of the cantonment area with significant cleared areas to the north and 80-ft-tall trees to the south.

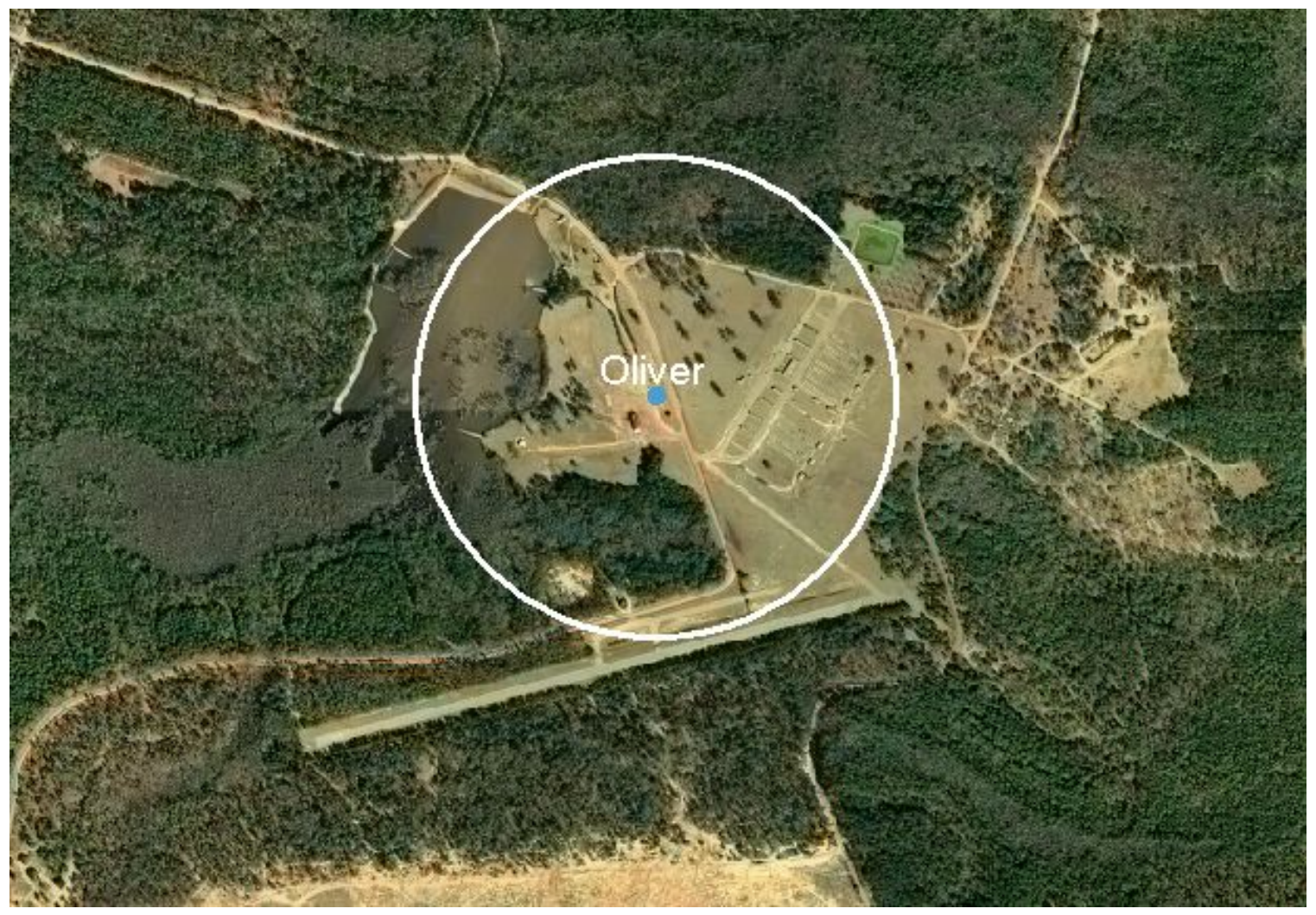

Figure 2.3. Aerial View of Glisson Site (Oliver) with 500-Mile Reference Circle 


\subsection{Measurement Methods}

Regional airshed characterization is generally a two-step process. First, a large-scale study is conducted to evaluate variability and unexpected sources, usually by saturating the area of interest with inexpensive special purpose monitors. Second, a few selected sites found during the first step that represent key portions of the study area are measured for multiple years to determine if an area is in compliance. During the second phase, a few permanent sites are established using U.S. Environmental Protection Agency (EPA)-approved federal reference methods (FRM) to collect 24-hour samples on a fixed $6^{\text {th }}$ day schedule. Throughout the sampling process, continuous monitoring may be used, which provides frequent measurements during the day. The continuous data are used in apportionment studies (coupled with wind direction for source determination) and to detect patterns (i.e., rush hour traffic) in PM productions.

Two types of gravimetric filter-based samplers were used in this study. All sites used battery powered, low-cost, portable special purpose monitors (MiniVols, Airmeterics, Grants Pass, OR) configured with either PM10 or PM2.5 size selective inlets. One FRM sampler (Partisol-Plus Model 2025 PM-2.5 Sequential Air Sampler Rupprecht \& Patashnick Co., Inc., Albany, NY) with a WINS 2.5 impactor was co-located with PM10 and PM2.5 MiniVols at the Shed site. Also at the Shed site, continuous PM10 data were collected using a 1400a Ambient Particulate Monitor TEOM (tapered element oscillating microbalance, Rupprecht \& Patashnick Co., Inc., Albany NY). The inlets for the Partisol-Plus, and co-located MiniVols are side by side, and the TEOM is within $50 \mathrm{ft}$.

At the five tower sites, the lower MiniVol was placed on the first cross bar at about $7 \mathrm{ft}$. The MiniVol with battery is $2 \mathrm{ft}$ tall, resulting in a typical inlet height of $9 \mathrm{ft}$. The upper Minivol was placed on the second from top landing of the tower at $80 \mathrm{ft}$. The upper portion of a typical Fort Stewart fire tower site is shown in Figure 3.1. Within the first 2 months of deployment of the MiniVols at the five fire towers, several occurrences of shortened sampling times were noted. It was determined that the periodic placement of Army communication equipment antennas on the upper portion of the towers would shut down the MiniVol timer. To minimize radio interference, the MiniVol electronics and battery were repositioned in a steel box located at ground level (Figure 3.2). The steel box was very effective in eliminating the RF-induced timer lockup.

Either a 3/8-in. polyethylene or 1/2-in. PVC pipe was used to conduct the inlet flow between the MiniVol pump inlet and the filter holder/air intake. When only the filter holder was placed on the cross bar at the lower height, the inlet height was approximately $7 \mathrm{ft}$. Placing the inlet height above $6 \mathrm{ft}$ also protected against animal disturbance since the sample sites were not fenced.

Data from three Georgia Department of Natural Resources (DNR) air-sampling sites located in or near Savannah were used for comparison with data from this study.

In 2001, two additional sites (Tree and West) were established at the installation boundary in areas with canopy height less than $30 \mathrm{ft}$. At these sites, a 25-ft pole was used to hold the upper height sampler (Figure 3.3). The 25-ft pole sites are labeled as West and Tree in Figure 1.1. At all sites, the MiniVols were powered by removable 12 VDC batteries. 


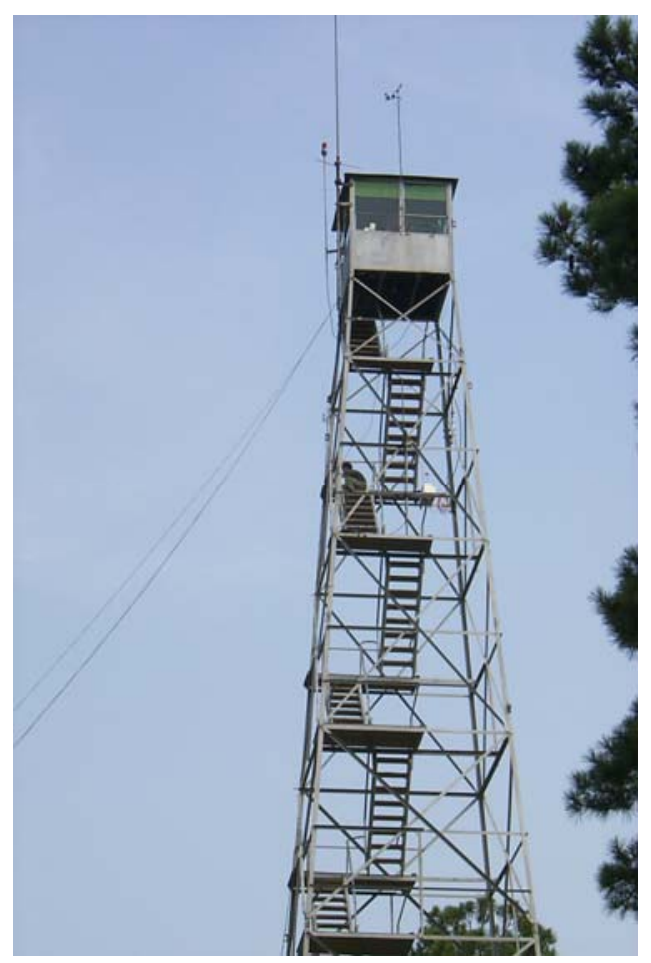

Figure 3.1. Typical Fire Tower with Staff Working at Upper Sampler Height

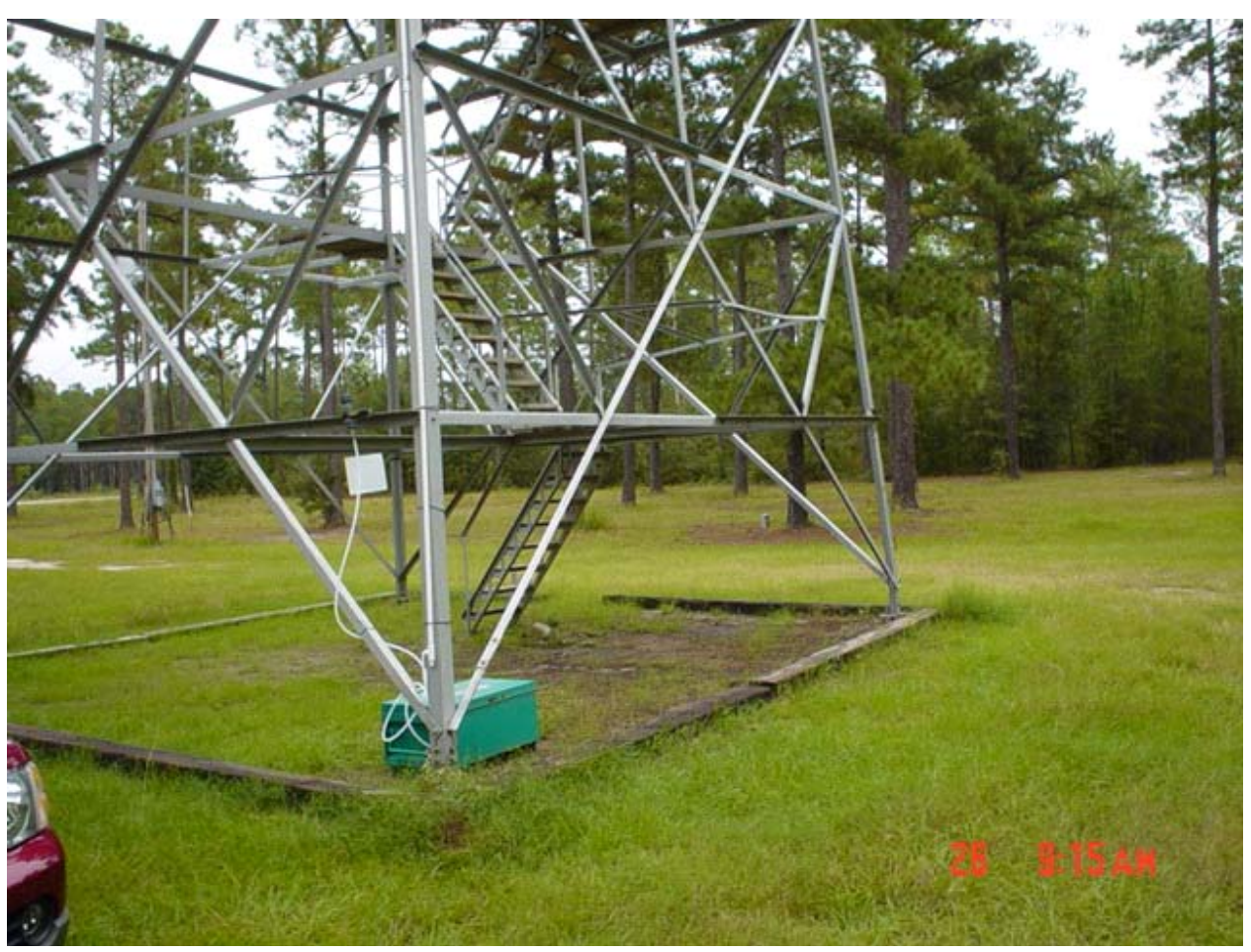

Figure 3.2. Job Site Box Containing MinVol and Tubing Running to Inlet Heads 


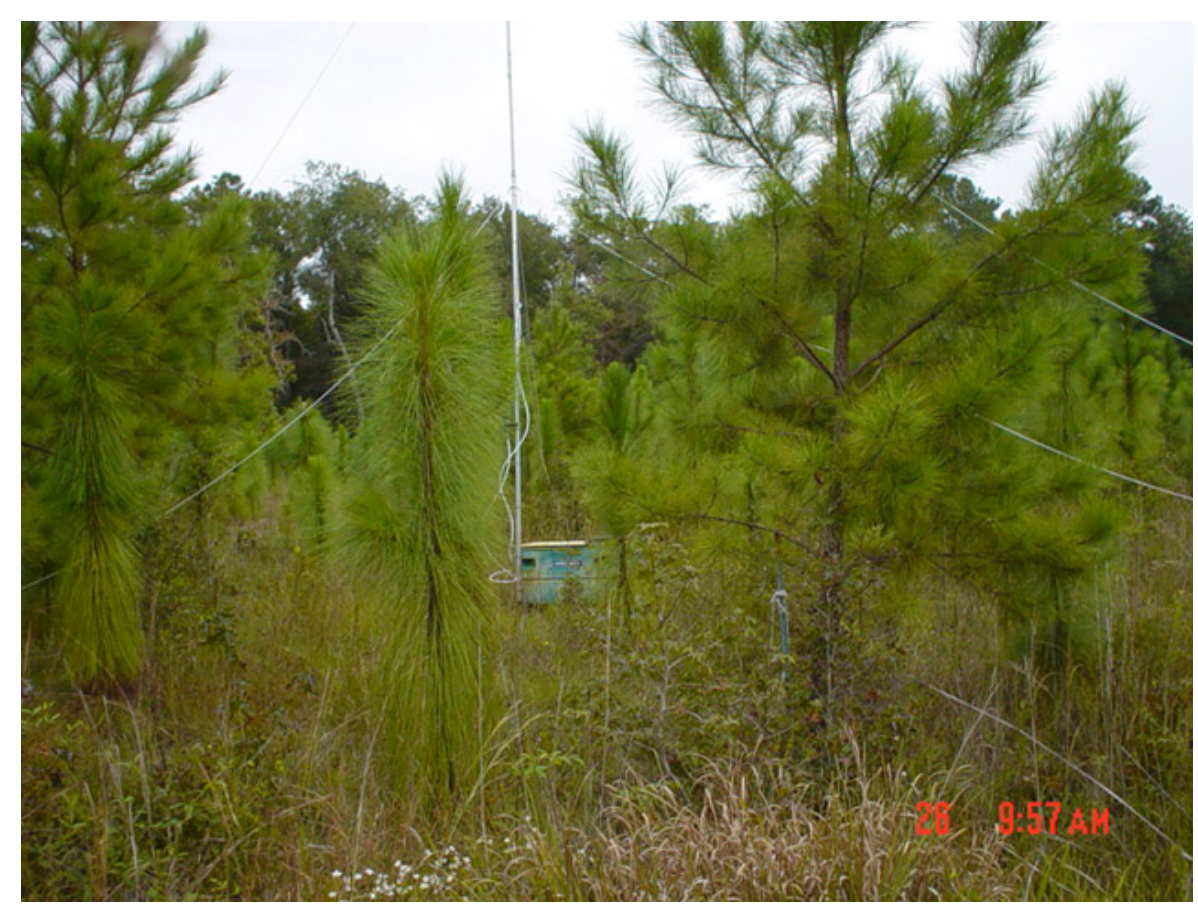

Figure 3.3. Tree Site with 25-Foot Pole Used to Hold PM Inlets

Meteorological data sets were collected using MetOne anemometers and CR10X data loggers (Campbell Scientific Inc., Logan, UT). Data were returned to our Richland, Washington, office using cell phones. Meteorological variables collected at 1-hour intervals or less included: air temperature, relative humidity, wind speed, and direction. Data logger power was obtained from commercial 110-volt lines at fire tower sites and from solar panels at the two non-tower boundary sites. Additional meteorological data, including precipitation and wind information, were obtained from the Directorate of Public Works (DPW)-Forestry.

To collect data from the many miles of roadways located on Fort Stewart, a mobile dust mapper (MDM) was constructed using global positioning systems (GPS), and wide-range nephelometers (DataRam, MIE Inc). These two instruments provided the core measurements of position and under vehicle PM (UVPM) concentration. An additional piece of equipment used during the road sampling included a data logger that was able to record GPS position (backup), relative wind speed, and wind direction. These sensors and equipment were installed on a midsize rental SUV (usually Ford Explorer, see Figure 3.4). Vehicle speed was $20 \mathrm{mph}$ during sampling. A video system directed toward the rear of the vehicle recorded trailing dust plume with GPS-derived coordinates overlaid on the recorded image. The audio signal on the video recorder contained comments about traffic encountered, unusual road conditions, and general observations.

The use of the MDM allowed rapid characterization of the relative emission of roadways under different environmental conditions. The PM concentration at each recorded position was analyzed in a geographical information system (GIS) (ArcGIS, ESRI, Redland, CA). For this study, GIS layers specific to Fort Stewart were provided by DPW-Environmental \& Natural Resources. 


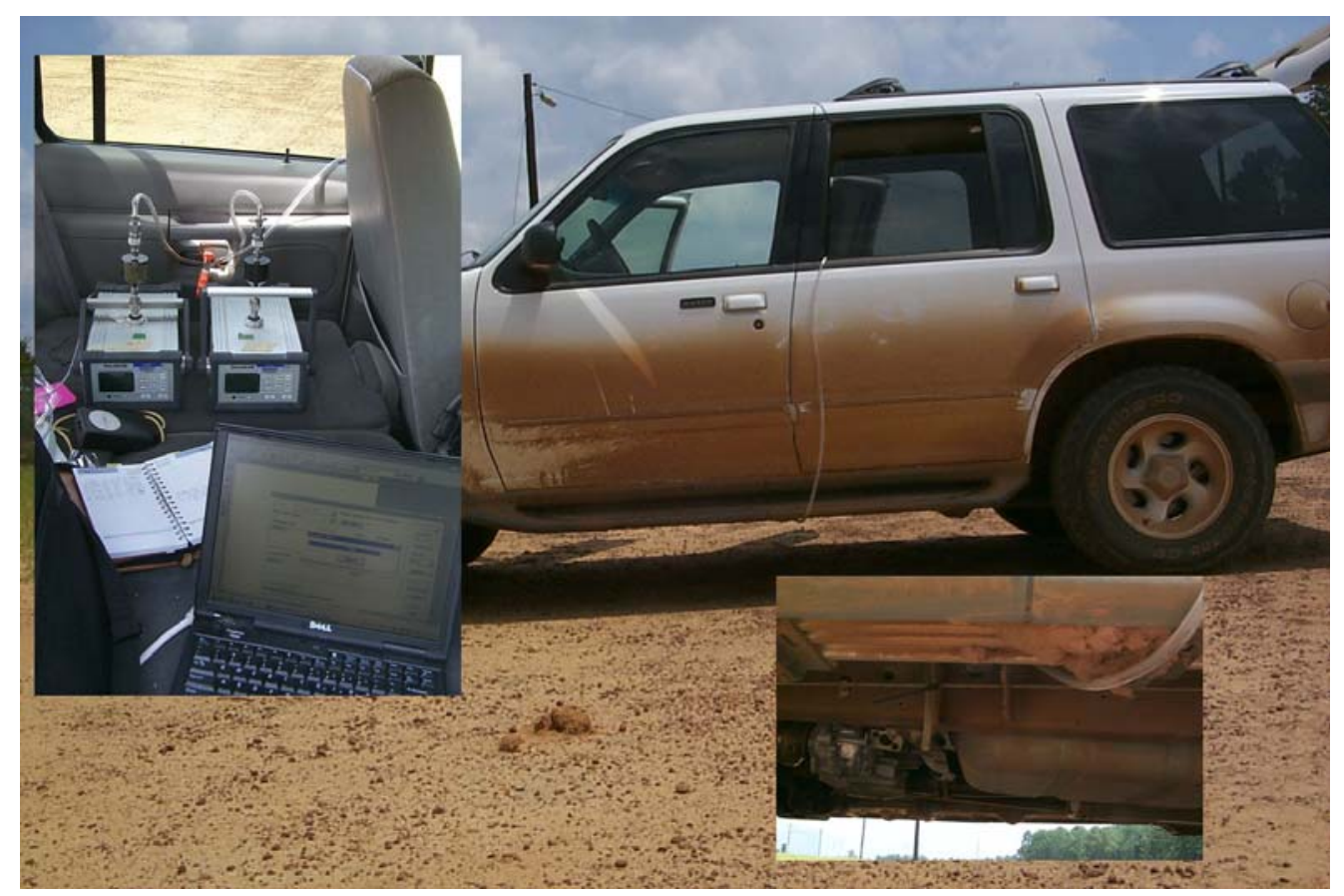

Figure 3.4. Mobile Dust Mapper Uses Nepholometers to Measure the UVPM Produced Behind the Front Wheel (inset under vehicle view of inlet tubing)

\subsection{Data Analysis}

Sampling data were compared using either one-way analysis of variance (ANOVA), where appropriate, or paired t-tests to assess differences between sample locations for data collected on the same day for the same time period. Comparisons were determined significant at critical values of 0.05 . 


\subsection{Results}

The PM2.5 values obtained within Fort Stewart boundaries ranged from the estimated lower limit of detection $\left(2 \mu \mathrm{g} / \mathrm{m}^{3}\right)$ to high PM values far greater than would be expected in a typical urban saturation sampling study. A maximum PM2.5 concentration of $1,566 \mu \mathrm{g} / \mathrm{m}^{3}$ was obtained at the lower elevation Lawson site on February 16, 2002. (The upper elevation sampler did not run that day.) This value was 24 times the daily average for PM2.5 and 10 times higher than the highest PM2.5 value found at Fort Irwin (dry desert environment). The large range observed in data is thought to be a result of localized training activities, (i.e., diesel generators parked next to samplers) and from controlled burns of the forest understory. Where supportive observations existed to identify specific training activities immediately adjacent to the PM monitor, the value was removed as being contaminated by a local source. Several high values are suspected to be due to adjacent generators, but direct evidence was not available to allow removal of the value from the analysis.

A primary objective of this study was to determine if the Fort Stewart airshed was different from that of nearby Savannah. Particulate matter has been monitored in the Savannah area since 1996. A similar mean concentration would indicate the area is one airshed, and that routine PM sampling at Fort Stewart would add little information to understanding the behavior of the coastal Georgia airshed. In the following four sections we review the PM concentrations measured onsite with similar data from Savannah; examine the MiniVol data (Appendix A) set to determine if there are differences in PM concentration across the installation; examine transport of PM across the installation boundary; and discuss an example of the training/prescribed burn analysis. The PM produced on tank trails is also discussed, and key areas generating PM under both dry and wet conditions are highlighted.

\subsection{Comparison of Fort Stewart and Savannah PM}

Table 4.1 compares Savannah data collected between July 2000 and October 2002 with Fort Stewart (Shed site) PM2.5 levels. During this period, there were 57 and 58 days of data for two Savannah PM sites (SAV17 and SAV91) that matched Shed site sequential sampler 24-hour filter runs. Evaluation of this data set indicated the Stewart Shed site was $11 \mu \mathrm{g} / \mathrm{m}^{3}$ compared to $15 \mu \mathrm{g} / \mathrm{m}^{3}$ for either Savannah site. In both cases, the Fort Stewart values were significantly lower $(\mathrm{p}=0.01$, paired $\mathrm{t}$ test $)$ than Savannah values. The overall mean at the Savannah sites for this time period $(217+214$ samples $)$ was $15 \mu \mathrm{g} / \mathrm{m}^{3}$, equivalent to the average of the small Savannah sub-sample used to compare with Fort Stewart data. The Fort Stewart and Savannah PM2.5 values were poorly correlated, possibly because of the large localized effect associated with prescribed burns, or it maybe the result of a day-use pattern that differs between that of an urban area and a military installation. A later discussion will show that the Shed site is quite representative of the entire installation area.

A similar comparison for PM10 can be made between August 2000 and May 2002. During this time, there were 44 comparable days with 24-hour averages of PM10 from both the Shed TEOM site and Savannah. The Savannah average was slightly higher at $19 \mu \mathrm{g} / \mathrm{m}^{3}$, compared to $18 \mu \mathrm{g} / \mathrm{m}^{3}$ for the Shed site. The means are not significantly different between the data sets, but the variance is quite large for the Shed site. The 24-hour TEOM averages are presented in the Appendix (Table A.3). The urban environment with few forested areas would be expected to experience less interception and trapping of PM 
Table 4.1. Data Available for Comparison of Fort Stewart (Shed Site) Sequential Sampler and Two Savannah PM2.5 Sites (SAV17 and SAV91) July 2000-October 2002

\begin{tabular}{|c|c|c|c|}
\hline DateRun & Shed Site & Sav17 & Sav91 \\
\hline $7 / 20 / 2000$ & 26.24 & 27.5 & 25.7 \\
\hline $7 / 21 / 2000$ & 13.69 & & \\
\hline $7 / 22 / 2000$ & 16.76 & & \\
\hline $7 / 23 / 2000$ & 12.32 & 14.1 & 13.2 \\
\hline $7 / 24 / 2000$ & 8.96 & & \\
\hline $7 / 25 / 2000$ & 10.08 & & \\
\hline $7 / 26 / 2000$ & 9.71 & 15.9 & 15.9 \\
\hline $7 / 27 / 2000$ & 8.09 & & \\
\hline $9 / 10 / 2000$ & 2.99 & & \\
\hline $9 / 11 / 2000$ & 6.43 & & \\
\hline $9 / 12 / 2000$ & 3.86 & & 23.9 \\
\hline $9 / 13 / 2000$ & 8.63 & & \\
\hline $10 / 7 / 2000$ & 12.53 & & \\
\hline $10 / 8 / 2000$ & 10.62 & & \\
\hline $10 / 9 / 2000$ & 5.98 & & 7.2 \\
\hline $10 / 10 / 2000$ & 4.52 & & \\
\hline $10 / 11 / 2000$ & 7.18 & 16.5 & \\
\hline $10 / 12 / 2000$ & 12.95 & 21.8 & 20.5 \\
\hline $10 / 13 / 2000$ & 21.58 & & \\
\hline $10 / 14 / 2000$ & 20.29 & & \\
\hline $10 / 17 / 2000$ & 20 & & \\
\hline $10 / 18 / 2000$ & 20.54 & & 35.8 \\
\hline $10 / 19 / 2000$ & 31.41 & & \\
\hline $10 / 21 / 2000$ & 10.58 & 12.9 & 14.3 \\
\hline $10 / 22 / 2000$ & 20.35 & & \\
\hline $10 / 23 / 2000$ & 25.35 & & \\
\hline $10 / 24 / 2000$ & 10.29 & 10.7 & \\
\hline $10 / 26 / 2000$ & 28.13 & & \\
\hline $10 / 27 / 2000$ & 20.95 & 19.7 & 18.8 \\
\hline $10 / 28 / 2000$ & 36.6 & & \\
\hline $10 / 29 / 2000$ & 28.51 & & \\
\hline $10 / 30 / 2000$ & 16.18 & 18.8 & 18.6 \\
\hline $10 / 31 / 2000$ & 19.5 & & \\
\hline $11 / 1 / 2000$ & 13.24 & & \\
\hline $11 / 2 / 2000$ & 16.35 & 25.6 & 23.6 \\
\hline $11 / 4 / 2000$ & 32.24 & & \\
\hline $11 / 5 / 2000$ & 33.28 & 33.9 & 32.1 \\
\hline $11 / 6 / 2000$ & 13.86 & & \\
\hline $11 / 7 / 2000$ & 11.49 & & \\
\hline $11 / 8 / 2000$ & 13.03 & 15.8 & 17.8 \\
\hline $11 / 9 / 2000$ & 6.18 & & \\
\hline $11 / 10 / 2000$ & 6.64 & & \\
\hline $11 / 11 / 2000$ & 24.27 & 11.4 & 10.8 \\
\hline
\end{tabular}

\begin{tabular}{|c|c|c|c|}
\hline \begin{tabular}{|l|} 
DateRun \\
\end{tabular} & Shed Site & Sav17 & Sav91 \\
\hline $11 / 13 / 2000$ & 94.56 & & \\
\hline $11 / 14 / 2000$ & 7.51 & 7.9 & 9.4 \\
\hline $11 / 15 / 2000$ & 7.97 & & \\
\hline $11 / 16 / 2000$ & 8.88 & & \\
\hline $11 / 17 / 2000$ & 12.99 & & \\
\hline $11 / 18 / 2000$ & 9.88 & & \\
\hline $11 / 19 / 2000$ & 3.78 & & \\
\hline $11 / 20 / 2000$ & 7.05 & & 9 \\
\hline $12 / 30 / 2000$ & 10.79 & & \\
\hline $12 / 31 / 2000$ & 6.39 & & \\
\hline $1 / 1 / 2001$ & 7.63 & & 15.1 \\
\hline $1 / 4 / 2001$ & 47.68 & & \\
\hline $1 / 5 / 2001$ & 21 & 55.3 & 29.4 \\
\hline $1 / 6 / 2001$ & 14.27 & & \\
\hline $1 / 7 / 2001$ & 12.74 & 28.2 & 28.2 \\
\hline $1 / 8 / 2001$ & 11.24 & & \\
\hline $1 / 9 / 2001$ & 12.41 & & \\
\hline $1 / 10 / 2001$ & 6.93 & 14.6 & 10.8 \\
\hline $1 / 11 / 2001$ & 15.81 & & \\
\hline $1 / 18 / 2001$ & 14.23 & & \\
\hline $1 / 19 / 2001$ & 4.65 & 10.8 & 10 \\
\hline $1 / 20 / 2001$ & 4.19 & & \\
\hline $1 / 21 / 2001$ & 5.02 & & \\
\hline $1 / 22 / 2001$ & 6.56 & 21.2 & 13.4 \\
\hline $1 / 23 / 2001$ & 4.58 & & \\
\hline $1 / 24 / 2001$ & 6.56 & & \\
\hline $1 / 25 / 2001$ & 8.67 & & 17.1 \\
\hline $1 / 28 / 2001$ & 47.63 & & \\
\hline $1 / 29 / 2001$ & 9.92 & & \\
\hline $1 / 30 / 2001$ & 3.86 & & \\
\hline $1 / 31 / 2001$ & 2.07 & 10.7 & 5.6 \\
\hline $2 / 1 / 2001$ & 6.18 & & \\
\hline $2 / 2 / 2001$ & 8.84 & & \\
\hline $2 / 3 / 2001$ & 8.05 & 12.2 & 13.8 \\
\hline $2 / 4 / 2001$ & 15.52 & & \\
\hline $2 / 9 / 2001$ & 11.37 & & 17.7 \\
\hline $2 / 10 / 2001$ & 4.98 & & \\
\hline $2 / 11 / 2001$ & 7.1 & & \\
\hline $2 / 12 / 2001$ & 6.68 & 9.7 & \\
\hline $2 / 13 / 2001$ & 5.15 & & \\
\hline $2 / 14 / 2001$ & 8.22 & & \\
\hline $2 / 15 / 2001$ & 5.52 & 12 & 10.6 \\
\hline $2 / 16 / 2001$ & 5.77 & & \\
\hline
\end{tabular}

\begin{tabular}{|r|r|r|r|}
\hline DateRun & Shed Site & Sav17 & Sav91 \\
\hline $2 / 27 / 2001$ & 10.46 & 12.5 & 13.6 \\
\hline $2 / 28 / 2001$ & 12.16 & & \\
\hline $3 / 1 / 2001$ & 11.04 & & \\
\hline $3 / 2 / 2001$ & 11.16 & 19.1 & 15.9 \\
\hline $3 / 3 / 2001$ & 6.22 & & \\
\hline $3 / 4 / 2001$ & 1.83 & & \\
\hline $3 / 5 / 2001$ & 5.73 & 11.5 & 8.2 \\
\hline $3 / 6 / 2001$ & 4.19 & & \\
\hline $3 / 13 / 2001$ & 3.78 & & \\
\hline $3 / 15 / 2001$ & 4.81 & & \\
\hline $3 / 16 / 2001$ & 4.61 & & \\
\hline $3 / 17 / 2001$ & 5.6 & 13.8 & 8.3 \\
\hline $3 / 18 / 2001$ & 11.74 & & \\
\hline $3 / 19 / 2001$ & 6.56 & & \\
\hline $3 / 20 / 2001$ & 2.28 & 5.8 & \\
\hline $3 / 24 / 2001$ & 13.73 & & \\
\hline $3 / 25 / 2001$ & 16.64 & & \\
\hline $3 / 26 / 2001$ & 6.27 & 13.2 & 10.5 \\
\hline $3 / 27 / 2001$ & 21.74 & & \\
\hline $3 / 28 / 2001$ & 11.54 & & \\
\hline $3 / 29 / 2001$ & 8.46 & 11.9 & 11.2 \\
\hline $3 / 30 / 2001$ & 4.69 & & \\
\hline $3 / 31 / 2001$ & 5.85 & & \\
\hline $4 / 7 / 2001$ & 12.12 & 16.7 & 12.8 \\
\hline $4 / 8 / 2001$ & 13.44 & & \\
\hline $4 / 9 / 2001$ & 14.69 & & \\
\hline $4 / 10 / 2001$ & 19.13 & 20 & 18.7 \\
\hline $4 / 11 / 2001$ & 16.56 & & \\
\hline $4 / 12 / 2001$ & 12.45 & & \\
\hline $4 / 13 / 2001$ & 12.66 & & \\
\hline $4 / 22 / 2001$ & 8.3 & 10.2 & \\
\hline $4 / 23 / 2001$ & 8.34 & & \\
\hline $4 / 24 / 2001$ & 7.39 & & \\
\hline $4 / 25 / 2001$ & 7.93 & 11.2 & \\
\hline $4 / 26 / 2001$ & 10.17 & & \\
\hline $4 / 27 / 2001$ & 12.66 & & \\
\hline $4 / 28 / 2001$ & 13.32 & 18.8 & 15.3 \\
\hline $4 / 29 / 2001$ & 12.03 & & \\
\hline $5 / 5 / 2001$ & 18.84 & & \\
\hline $5 / 6 / 2001$ & 16.97 & & \\
\hline $5 / 7 / 2001$ & 10.58 & 8.7 & \\
\hline $5 / 8 / 2001$ & 10.29 & & \\
\hline $5 / 9 / 2001$ & 69.92 & & 11.4 \\
\hline & & & \\
\hline
\end{tabular}


Table 4.1. (contd)

\begin{tabular}{|r|r|r|r|}
\hline DateRun & Shed Site & Sav17 & Sav91 \\
\hline $5 / 10 / 2001$ & 13.86 & & 21.8 \\
\hline $5 / 11 / 2001$ & 15.35 & & \\
\hline $5 / 12 / 2001$ & 16.27 & 18.9 & \\
\hline $5 / 13 / 2001$ & 20.75 & 21.5 & 20.5 \\
\hline $5 / 14 / 2001$ & 28.88 & & \\
\hline $5 / 15 / 2001$ & 18.63 & & \\
\hline $5 / 16 / 2001$ & 23.07 & & 31.3 \\
\hline $5 / 17 / 2001$ & 31.87 & & \\
\hline $5 / 18 / 2001$ & 29 & & \\
\hline $5 / 19 / 2001$ & 21.83 & 22.4 & 18.1 \\
\hline $5 / 27 / 2001$ & 33.07 & & \\
\hline $6 / 16 / 2001$ & 14.65 & & \\
\hline $6 / 17 / 2001$ & 17.63 & & \\
\hline $6 / 18 / 2001$ & 14.5 & 15.6 & \\
\hline $6 / 20 / 2001$ & 13.2 & & \\
\hline $6 / 21 / 2001$ & 13.49 & 13.5 & \\
\hline $8 / 2 / 2001$ & 2.57 & 9.9 & 9.1 \\
\hline $8 / 4 / 2001$ & 3.36 & & \\
\hline $8 / 5 / 2001$ & 22.74 & 7.7 & 8.2 \\
\hline $8 / 6 / 2001$ & 4.4 & & \\
\hline $8 / 7 / 2001$ & 2.74 & & \\
\hline $8 / 8 / 2001$ & 2.24 & 13.7 & 12.5 \\
\hline $8 / 9 / 2001$ & 2.24 & & \\
\hline $8 / 10 / 2001$ & 3.78 & & \\
\hline & & & \\
\hline
\end{tabular}

\begin{tabular}{|r|r|r|r|}
\hline DateRun & Shed Site & Sav17 & Sav91 \\
\hline $8 / 11 / 2001$ & 10.83 & 13.1 & 12.3 \\
\hline $8 / 12 / 2001$ & 3.61 & & \\
\hline $8 / 13 / 2001$ & 21 & & \\
\hline $8 / 14 / 2001$ & 29.05 & 14.7 & 13.6 \\
\hline $8 / 15 / 2001$ & 2.16 & & \\
\hline $8 / 16 / 2001$ & 3.07 & & \\
\hline $8 / 17 / 2001$ & 2.74 & & 20.4 \\
\hline $8 / 19 / 2001$ & 2.32 & & \\
\hline $8 / 20 / 2001$ & 9.42 & 13.1 & 12.8 \\
\hline $8 / 21 / 2001$ & 2.37 & & \\
\hline $8 / 22 / 2001$ & 2.49 & & \\
\hline $8 / 24 / 2001$ & 2.03 & & \\
\hline $9 / 3 / 2001$ & 18.51 & & \\
\hline $9 / 8 / 2001$ & 1.08 & & \\
\hline $9 / 9 / 2001$ & 1.29 & & \\
\hline $9 / 27 / 2001$ & 7.88 & & \\
\hline $9 / 28 / 2001$ & 7.05 & 18.8 & 18.4 \\
\hline $9 / 29 / 2001$ & 6.89 & & \\
\hline $9 / 30 / 2001$ & 6.97 & & \\
\hline $10 / 1 / 2001$ & 6.27 & 13.3 & 12 \\
\hline $10 / 2 / 2001$ & 7.63 & & \\
\hline $10 / 3 / 2001$ & 10.33 & & \\
\hline $10 / 4 / 2001$ & 6.85 & 11.7 & 12 \\
\hline $10 / 23 / 2001$ & 5.06 & & \\
\hline & & & \\
\hline
\end{tabular}

\begin{tabular}{|r|r|r|r|}
\hline DateRun & Shed Site & Sav17 & Sav91 \\
\hline $10 / 24 / 2001$ & 5.35 & & \\
\hline $10 / 25 / 2001$ & 9.09 & 8.1 & 6.5 \\
\hline $10 / 26 / 2001$ & 40.5 & & \\
\hline $10 / 27 / 2001$ & 8.26 & & \\
\hline $10 / 28 / 2001$ & 11.83 & 8.5 & 9.5 \\
\hline $10 / 29 / 2001$ & 8.71 & & \\
\hline $10 / 30 / 2001$ & 5.29 & & \\
\hline $5 / 14 / 2002$ & 9.05 & 8.4 & 8.5 \\
\hline $5 / 14 / 2002$ & 9.05 & & 8.5 \\
\hline $5 / 26 / 2002$ & 7.93 & & \\
\hline $5 / 26 / 2002$ & 7.93 & & \\
\hline $5 / 30 / 2002$ & 7.8 & & \\
\hline $6 / 1 / 2002$ & 13.03 & 13.6 & 13 \\
\hline $6 / 1 / 2002$ & 13.03 & 11.8 & 13 \\
\hline $6 / 6 / 2002$ & 11.87 & & \\
\hline $6 / 10 / 2002$ & 6.97 & 6.7 & 7 \\
\hline $6 / 13 / 2002$ & 5.52 & 11.6 & 8.9 \\
\hline $6 / 13 / 2002$ & 5.52 & 9.5 & 8.9 \\
\hline $6 / 25 / 2002$ & 8.92 & 9 & \\
\hline $6 / 25 / 2002$ & 8.92 & 8.8 & \\
\hline $10 / 25 / 2002$ & 12.99 & & \\
\hline $10 / 30 / 2002$ & 4.4 & & \\
\hline & & & \\
\hline
\end{tabular}

material. The Shed site is surrounded by forest, and it is reasonable to expect lower low concentrations of PM. The greater variability is also consistent with the intermittent use pattern associated with training or prescribed burn events, as compared to the more consistent daily urban activities that generate PM. TEOM data can be lower than filter based data because of the elevated collection temperature.

\subsection{PM Values on Fort Stewart}

Using only MiniVol data from the Shed site, there were 73 days with both PM10 and PM2.5 values available for comparison. For these 73 days, the average PM2.5 concentration was $15.7 \mu \mathrm{g} / \mathrm{m}^{3}$, which is $87 \%$ of the PM10 concentration of $17.9 \mu \mathrm{g} / \mathrm{m}^{3}$. There was little difference between average MiniVol PM2.5 data collected at the Fort Stewart sampling sites (Figure 4.1). Using all MiniVol PM2.5 values, except for three extremely high values over $870 \mu \mathrm{g} / \mathrm{m}^{3}$ (likely due to nearby diesel generators), the mean PM value at the lower sampling height was $14.4 \mu \mathrm{g} / \mathrm{m}^{3}$, and the upper height was $15.5 \mu \mathrm{g} / \mathrm{m}^{3}$.

Figure 4.1 shows that only Glisson and Richmond Hill had lower PM values at the higher sampling height than at the lower height. This indicates the source is close to the towers, and that the PM is not arriving in a well-mixed profile. A possible explanation is that both sites have adjacent dirt roads and 


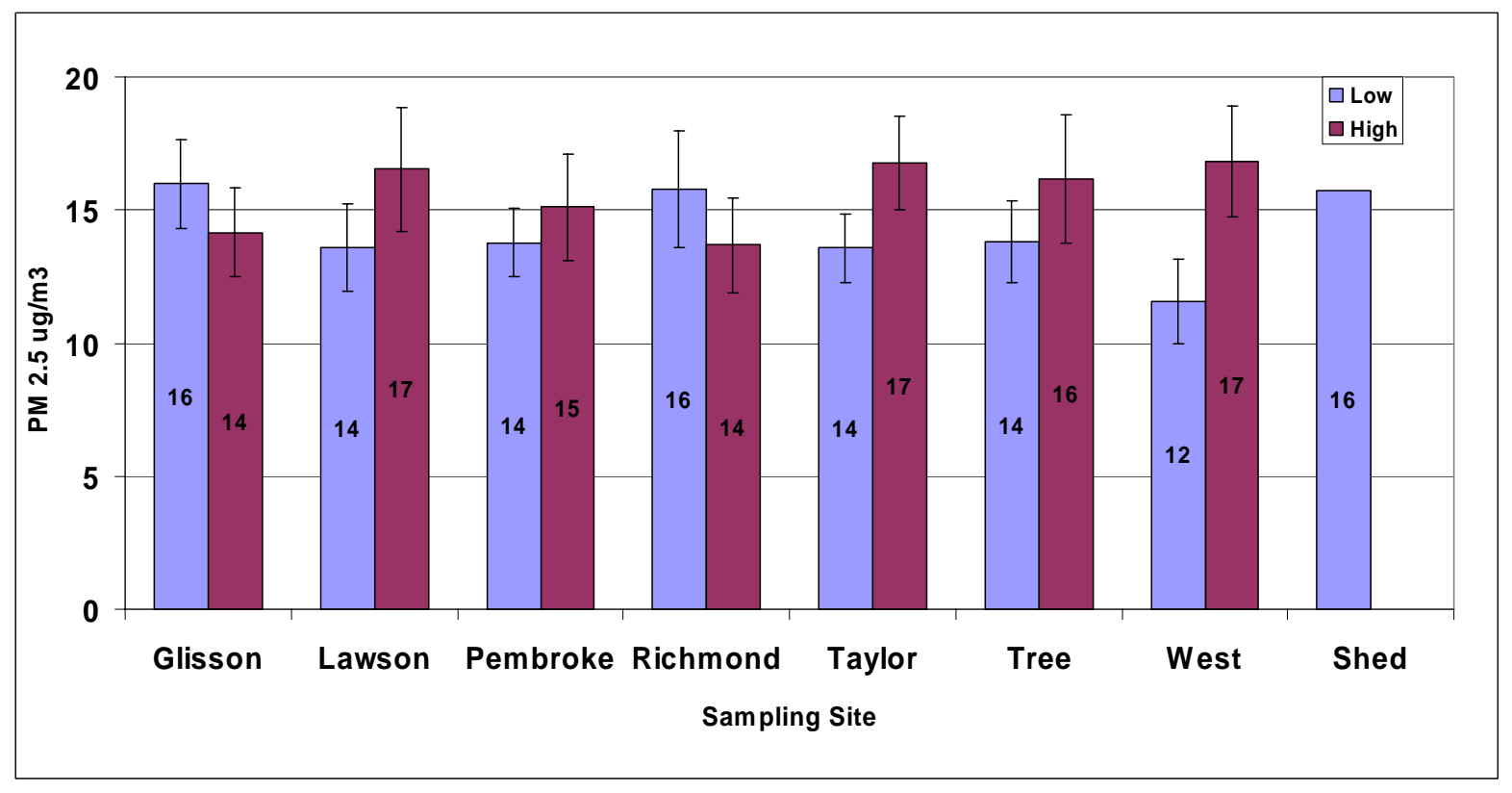

Figure 4.1. PM2.5 Values for Eight Measurement Sites and Two Heights (error bars are \pm 1 standard error)

have been observed to experience higher levels of vehicle traffic than many of the dirt roads located on the installation. At Glisson, the road is the major access to Camp Oliver from the west; tactical vehicles often were observed on this route, but there was little public traffic at this site. There was also a large graveled parking lot at the Glisson site where we occasionally observed heavy equipment parked. At the Richmond Hill site, the road provides public access to hunting and fishing with more civilian vehicle traffic than tactical vehicle use observed during filter change visits.

At two sites (Shed and Glisson) where the sampling area was more open (no tall trees), the lower elevation PM concentration was above $16 \mu \mathrm{g} / \mathrm{m}^{3}$. Values for the Richmond site also were above $16 \mu \mathrm{g} / \mathrm{m}^{3}$, but as mentioned previously, a dirt road nearby is used by both the Army and public. The mixing of ground level air with upper levels is not restricted by a tall tree canopy at these two sites.

\subsection{Transport of PM Across Installation Boundary}

The PM data from sites near the installation boundary was examined to determine if air leaving the installation contains more or less PM than air entering the installation. As shown in Figure 4.1, the air below the canopy generally had a lower concentration of PM2.5 particles than the air near the top of the forest canopy (not significant at $\mathrm{p}=0.05$ ). To minimize the local effect of the trees, the transport onto and off of the installation was determined from the upper sampling height. The MiniVol concentration values can be associated with the average wind vector (direction) occurring during the 24-hour sample collection time period. Three of the fire tower sites were close enough to the installation perimeter to justify a simple separation of wind direction into two 180-degree sectors, referred to as incoming and outgoing 
wind direction. The upper-elevation PM2.5 concentration was plotted against wind direction (Figures 4.2, 4.3, and 4.4) to evaluate whether lower or higher concentrations corresponded to inflow or outflow of air to the installation.

The Richmond site, located on the east end of the installation, is surrounded by tall trees. Comparing the Richmond site PM2.5 data for the upper height with respect to wind direction in (Figure 4.2) shows that the average PM2.5 values for each sector were $12.1 \mu \mathrm{g} / \mathrm{m}^{3}$ for incoming air and $8.4 \mu \mathrm{g} / \mathrm{m}^{3}$ for outgoing air. These values are not significantly different.

The Pembroke site is approximately 500 miles south of the northern installation border. Air flow out of the installation was represented as directions ranging from 90 to 270 degrees. The average PM concentration of air leaving the installation at Pembroke was $15.2 \mu \mathrm{g} / \mathrm{m}^{3}$ as compared to $13.3 \mu \mathrm{g} / \mathrm{m}^{3}$ incoming. The outflow average was dominated by a single large value of $111 \mu \mathrm{g} / \mathrm{m}^{3}$ occurring on October 29, 2000 (Figure 4.3). If this high value were removed, the outflow average would drop to $10.6 \mu \mathrm{g} / \mathrm{m}^{3}$. The difference is not significant either with or without the $111 \mu \mathrm{g} / \mathrm{m}^{3}$ value included. All the upper height PM samples obtained on October $29^{\text {th }}$ are elevated, and the source for the elevated PM is likely to be off the installation. The Range Facility Management Support System (RFMSS) indicated a small number of troops were in the field in training areas near cantonment, and a small 15-acre wildfire occurred near the Lawson site, but winds only blew from the location of the fire toward the Pembroke site for a few hours just before dawn, most likely prior to the fire starting.

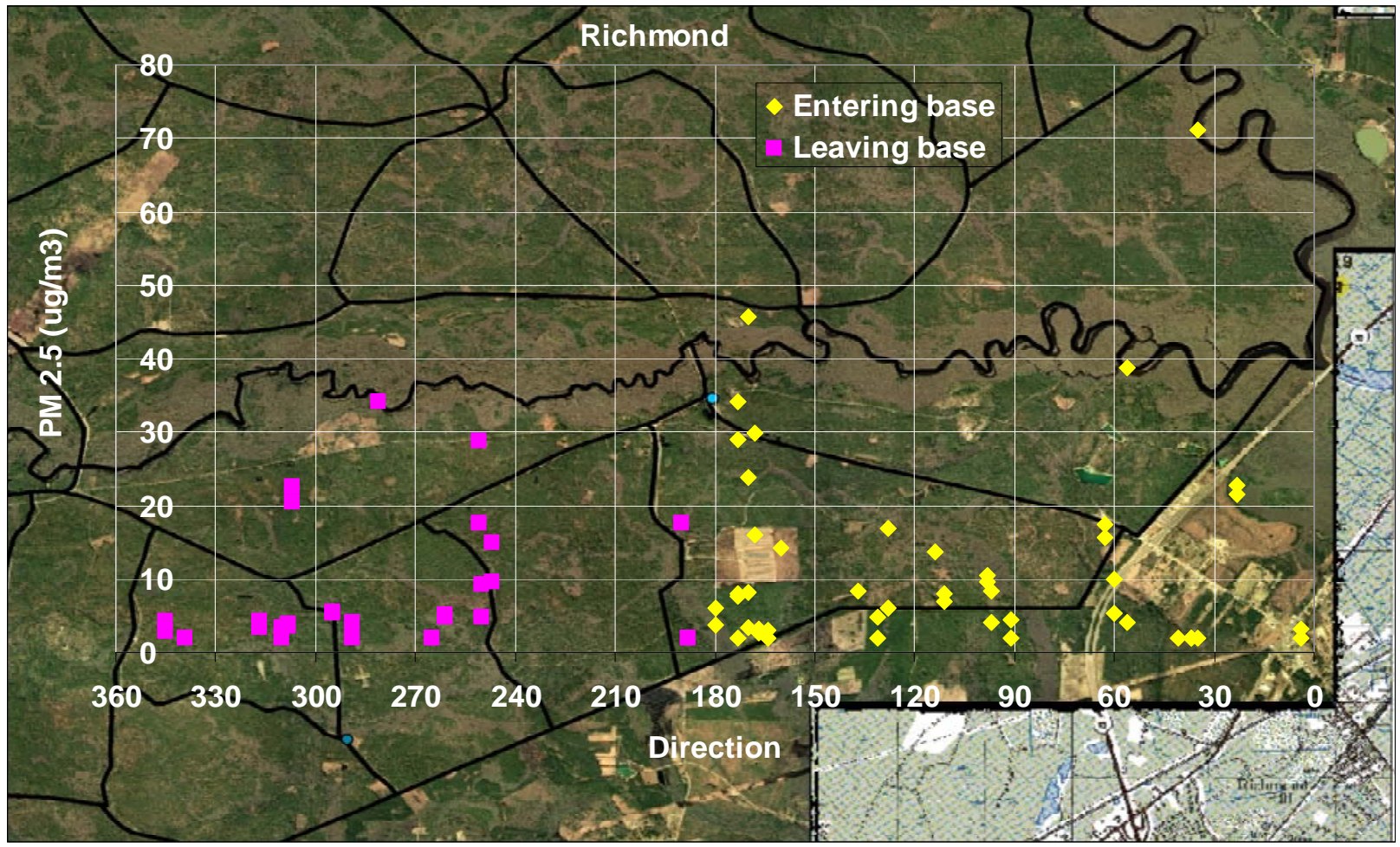

Figure 4.2. Richmond PM2.5 Concentrations Compared to Wind Direction. Yellow diamonds represent incoming air flow; violet squares represent outflow. 


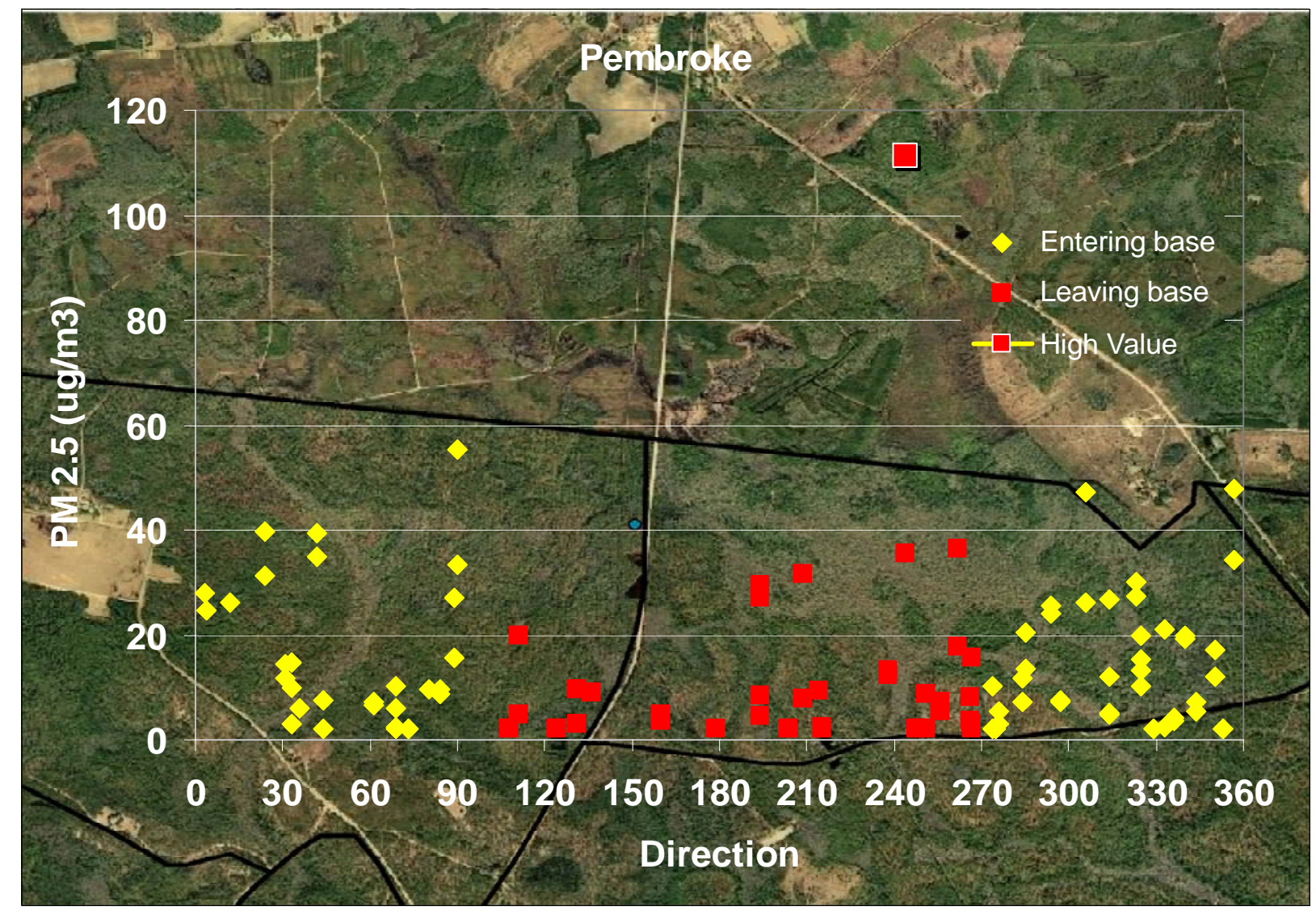

Figure 4.3. Pembroke PM Values and Wind Direction

The West site, as seen in Figure 4.4, had significant agricultural activity south and west of the measurement site. The average PM concentration of the outflow at $11.4 \mu \mathrm{g} / \mathrm{m}^{3}$ was significantly less $(\mathrm{p}=0.05)$ than the inflow average of $23.3 \mu \mathrm{g} / \mathrm{m}^{3}$. Although not conclusive from such a small sampling, the two higher PM2.5 concentrations seemed to be coming from the general direction of the farmed land and a poultry farm located just outside the 1,640 ft radius at about 220 degrees (Figures 2.2 and 4.4). Poultry farms can be a major source of PM material because of continual disturbance of the floor surface (food, soil, and feces) by the birds and by large cooling fans used to control temperatures within the poultry shed. Lim et al. (2003) observed a daily average PM2.5 concentration of 39 and $518 \mu \mathrm{g} / \mathrm{m}^{3}$ for PM2.5 and PM10, respectively, from a laying hen house.

\subsection{Comparison of Training and PM2.5}

One study objective was to determine whether troop and vehicle concentrations were related to PM concentrations. Training activities, as captured by the RFMSS database, were used to track the use of training areas at Fort Stewart. The table "Uprocess" within RFMSS was queried to provide the total 


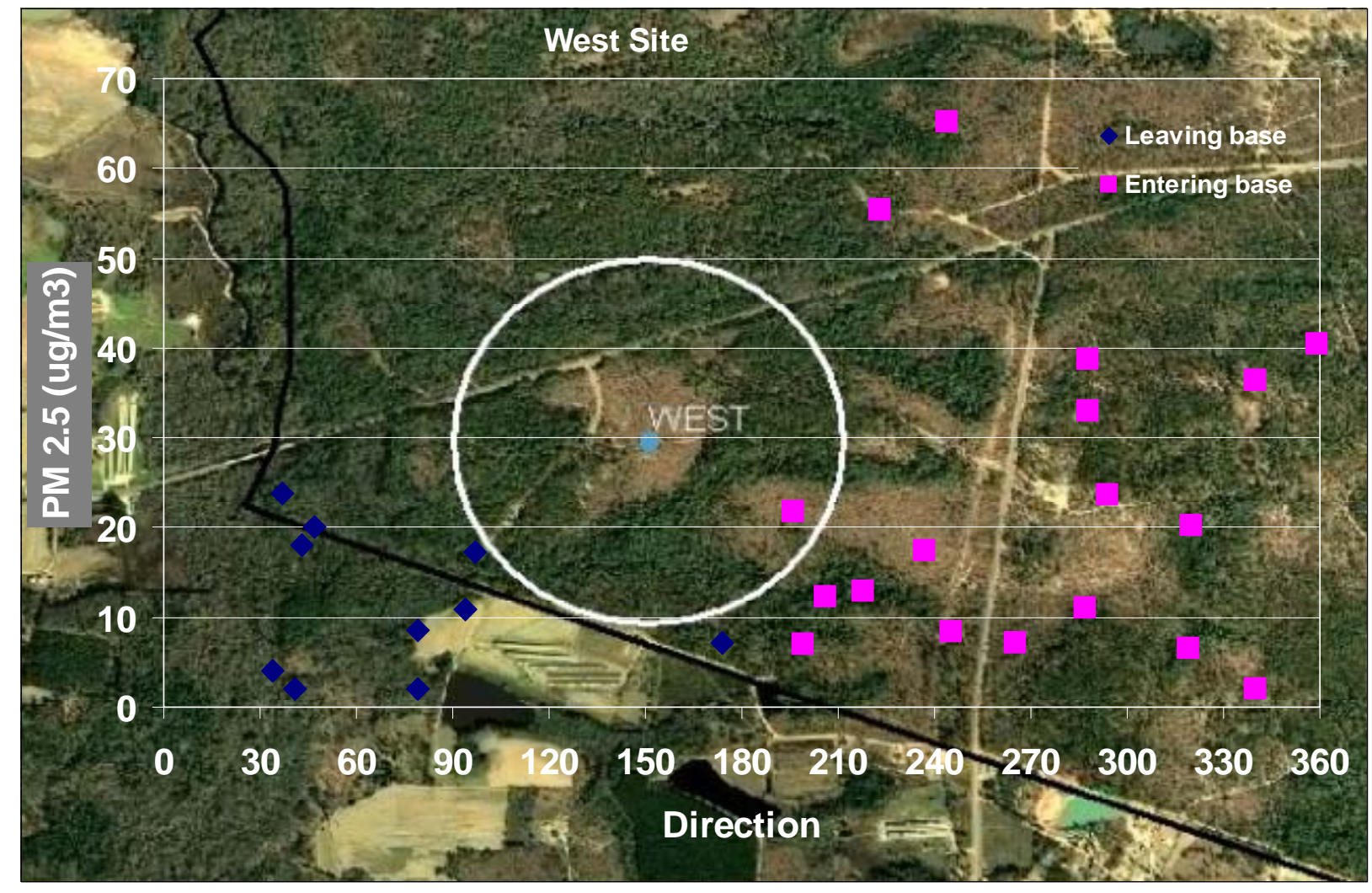

Figure 4.4. West Site PM2.5 Concentrations Compared to the Wind Direction

number of troops in the field each day. Map coordinates were assigned to the center of each training area. More than one training area can be in use within a 24-hour period, and more than one group can be using the same area. All available PM2.5 (Table A.2) values collected at the towers and pole sites were averaged for each day and compared against troop number ('ActNumPers') in the field summed by day. Figure 4.5 illustrates the lack of a clear relationship between PM2.5 concentration (y axis) and climatic season (date $\mathrm{x}$ axis), troop number (bubble size), days since precipitation (color). It is not surprising to see a wide range of troop numbers at low PM concentrations as rainy weather will keep PM concentration low, irrespective of the number of troops in the field. The 2000 spring and summer drought had a few higher average PM2.5 values than subsequent years.

The RFMSS database was queried from within ArcGIS, facilitating the display of 'ActNumPers' and troop position relative to the sampling sites. This allowed for a more detailed examination of the data to detect any relationship between PM source and specific sampler PM values. For example, we compared measurements from the sequential sampler located at the Shed site with troop locations. On January 28, 2001, an elevated PM2.5 value of $47 \mu \mathrm{g} / \mathrm{m}^{3}$ was measured at the Shed site. Figure 4.6 shows an example of a spatial plot with troop numbers and number of wheeled vehicles assigned according to related fields in 'Uprocess,' a table within the RFMSS database. The yellow points (January 28, 2001) represent where an entrained particle of the air that passed through the Lawson site would have been 15 minutes previously. This value was determined by multiplying the orthogonal vector components of wind direction by the wind speed. Most points are north and west of the Lawson site. The HYSPLIT back trajectory is 


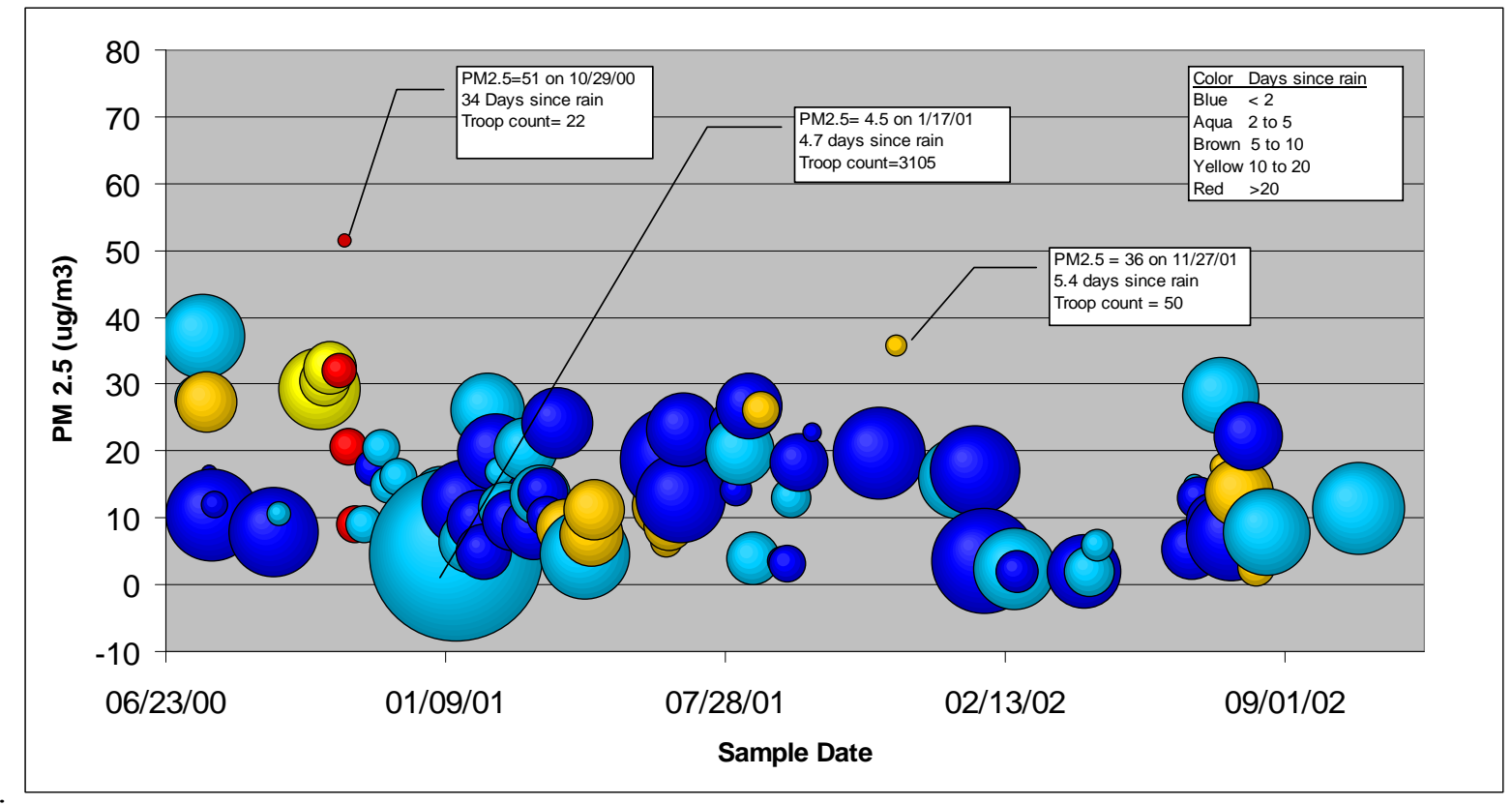

Figure 4.5. Scatter Plot Relating PM2.5 Concentration to Troop Number and Days Since Rain

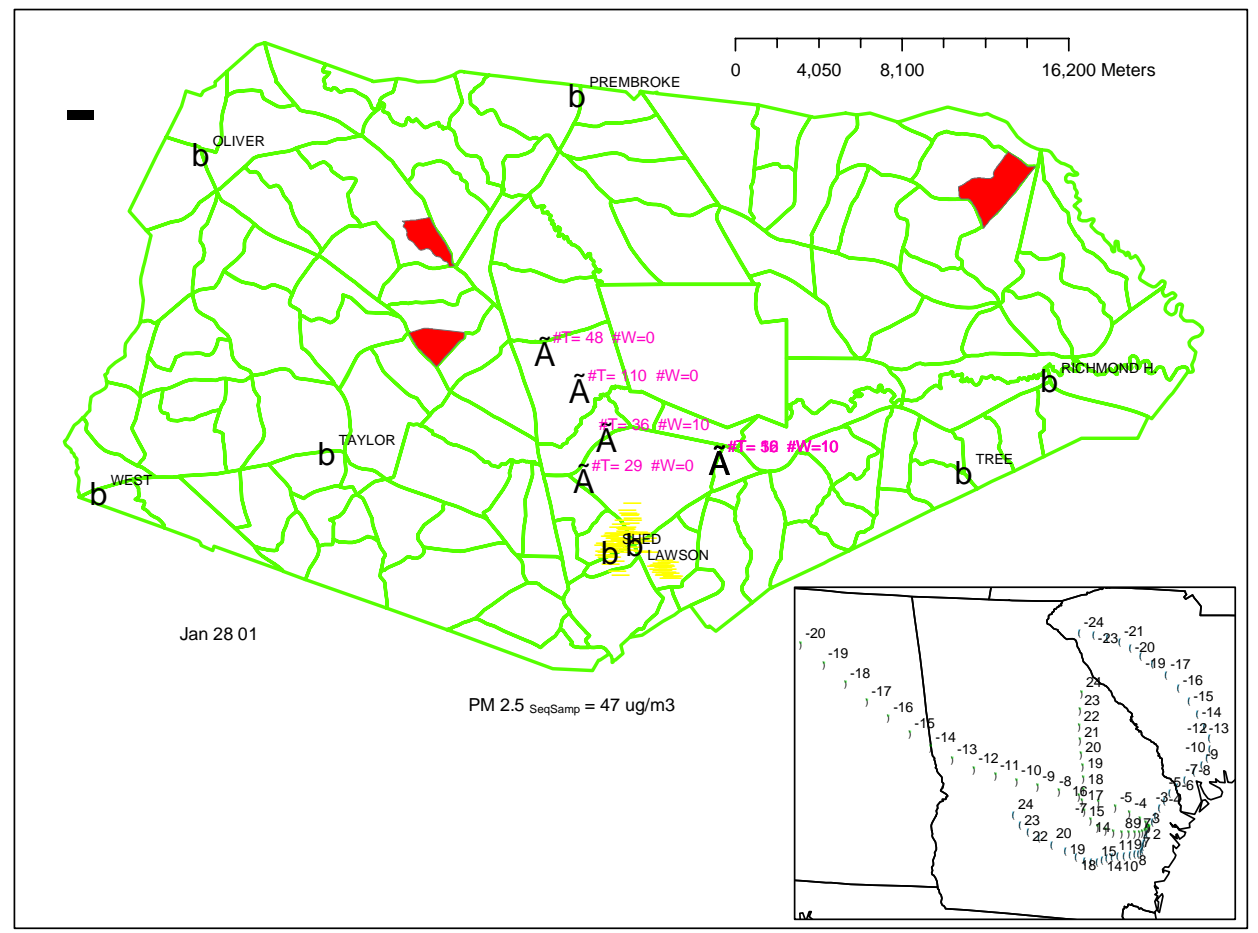

Figure 4.6. Troop Levels and Prescribed Burns on January 28, 2001 
shown in the inset as diamonds (ground level) and circles (500 m elevation). The points represent where a particle came from at 1 -hour time steps, with the ending point being the Shed site at noon. The groundlevel values were closer together, as expected, indicating lower wind speeds near the ground surface. The red areas represent prescribed burns that occurred that day. On January 28, 2001, either prescribed burns or training could have contributed to the elevated PM2.5 value $\left(47.6 \mu \mathrm{g} / \mathrm{m}^{3}\right)$ from the sequential sampler located at the Shed site. Sequential sampler PM2.5 values were 9.9 and $3.8 \mu \mathrm{g} / \mathrm{m}^{3}$ on the $29^{\text {th }}$ and $30^{\text {th }}$ of January 2001. Figure 4.7 indicates that on January 29, 2001, there were still troops in the field, and three additional prescribed burn sites were ignited. The low sequential sampler value of 9.9 is a result of the winds arriving primarily from the south with little chance of smoke from the prescribed burns.

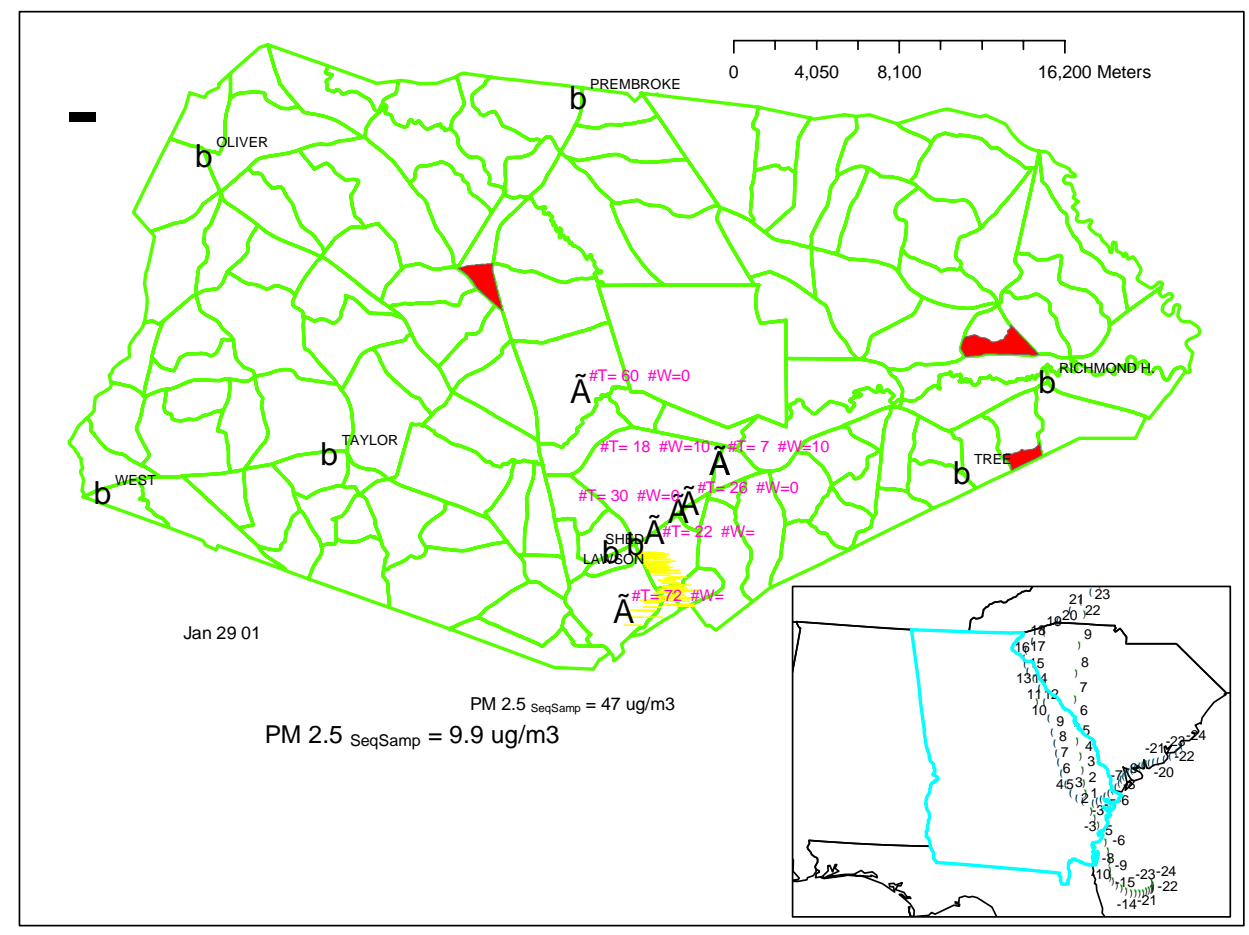

Figure 4.7. Troop Levels and Prescribed Burns on January 29, 2001

On May 8, 2002, fires in the Okefenokee Swamp in southern Georgia sent a smoke plume in a northeasterly direction passing over Fort Stewart. The smoke plume was visible in a GOES satellite image obtained from the NOAA Fire Weather Information Center (Figure 4.8). On May 8, 2002, there were four MiniVol PM2.5 measurements available and hourly PM10 data from the TEOM. Three heavily treed sites, Pembroke, Taylor, and Tree had very low PM2.5 values $\left(<6 \mu \mathrm{g} / \mathrm{m}^{3}\right)$. The MiniVol at Glisson showed a relatively high value of $77.6 \mu \mathrm{g} / \mathrm{m}^{3}$ and the 24 hour average PM10 for the TEOM at the Shed site was $45.3 \mu \mathrm{g} / \mathrm{m}^{3}$. These two sites have a much larger area free of trees which would promote boundary layer mixing down to the 2-mile sampling height. Winds at the Lawson site were generally from the south and speeds were low ( $<2 \mathrm{mph}$ for most of the daylight hours). 


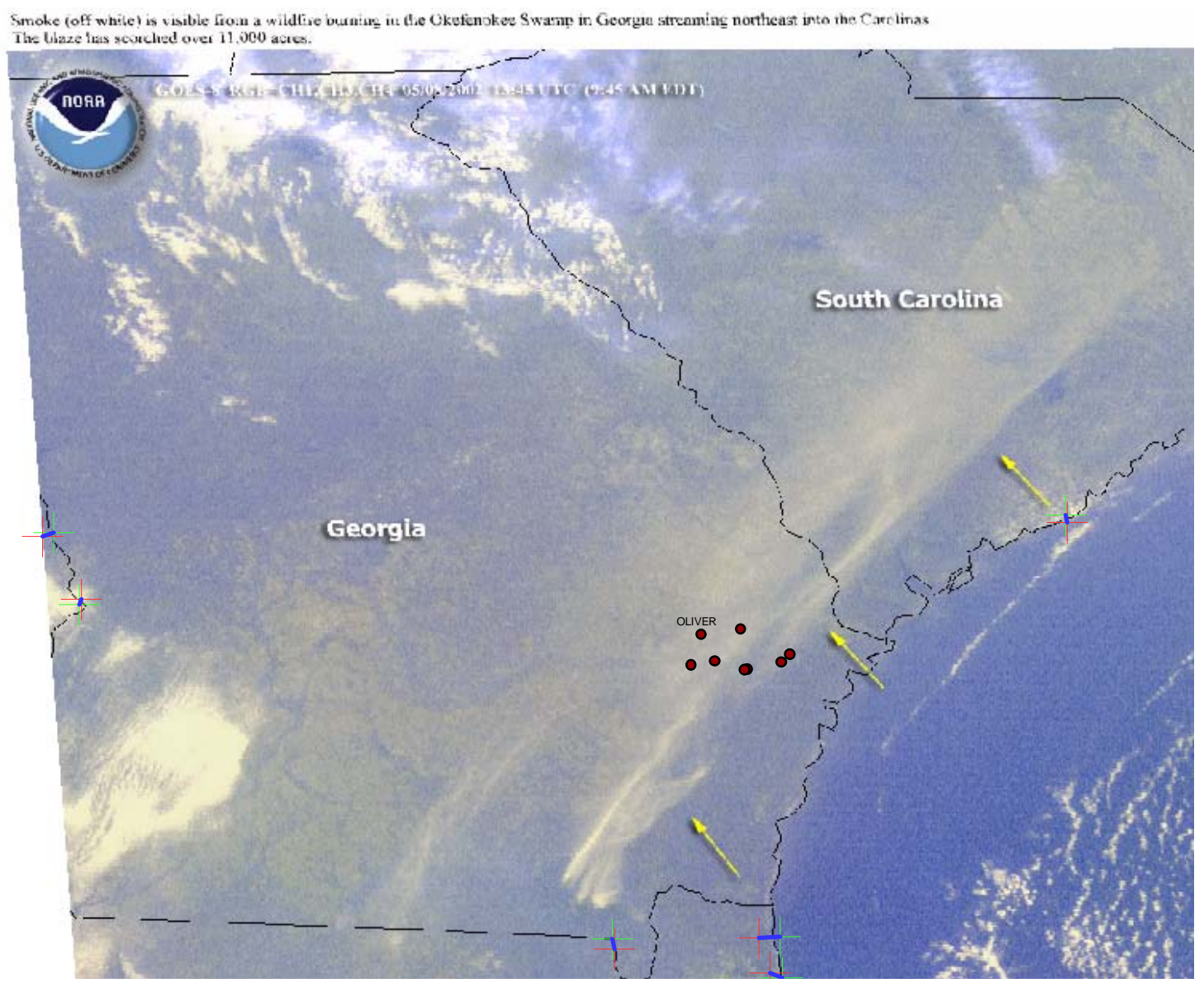

Figure 4.8. Smoke Plume Originating in the Okefenokee Swamp Passing Over the Fort Stewart Sampling Sites on May 8, 2002

\subsection{Tank Trail PM Production}

The most obvious PM emission outside of cantonment occurs from vehicles traveling on dirt roads or tank trails. Often, a facility may be required to obtain a permit for expected releases from short-term construction activities or long-term training activities. When unpaved roads are involved in the activities, permit applicants will use the AP-42 emission factors for the closest type of activity listed (USEPA 1995). The EPA recommends using site-specific emission factors because the AP-42 values are based on averages.

The current emission factor equation in AP-42 includes factors for silt content, vehicle speed, vehicle weight, and number of wheels. The calculated emission is adjusted by a particle size multiplier (increases to 1 at $30 \mu \mathrm{m}$ ) appropriate for the emission size fraction of interest. During the permitting process, the emissions might be calculated for the amount of miles of road surface with different road surface silt content. The simplest approach is to estimate silt content from soil map. This may not reflect the actual 
emissions for reasons such as: the road bed may not be derived of local materials, might be from some unknown depth in the soil profile, may have previously received stabilizer treatment, or may have been broken down by extensive vehicle traffic.

Sampling and analyzing surface soil samples at sufficient density to characterize hundreds of miles of road surface was not cost effective. We used the MDM to record vehicle location and measure UVPM. These data were collected using an SUV four-wheel drive vehicle, where the actual sampling occurred behind the front wheels and ahead of any significant motor emissions. This point source (1-second instantaneous UVPM concentrations often thousands of times higher than and having the same units as ambient air monitoring) should not be confused with ambient PM monitoring. Ambient monitoring is generally a 24-hour average from 2 miles or higher located in a well-mixed air stream representative of a large spatial extent.

The main tank trails (Routes 5, 129, 40, and 144) on the west side of the installation were sampled on June 28, 29, and July 1, 2002. These three separate data sampling runs form a triangle in Figure 4.9, which illustrates relative increase in PM production as colors change from green (low) to red (high). The blue background represents the loamy soil types, and the white areas are coarser soils with less silt. The areas with high relative concentrations near the state highway are prime candidates for remediation. The

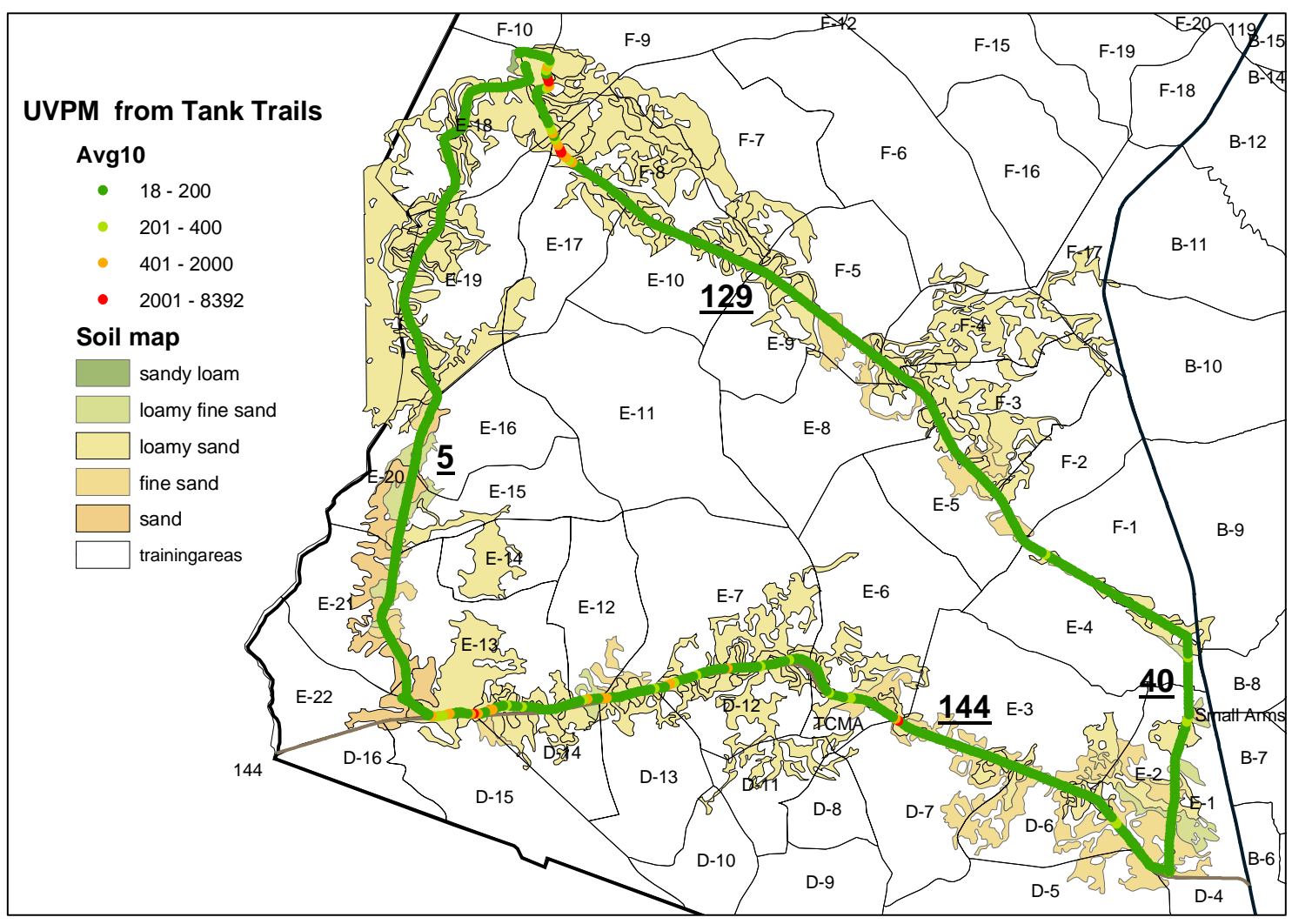

Figure 4.9. Relative PM10 Production from Tank Trails Between June 28 and July 1, 2002 
western area of Fort Stewart receives the greatest training pressure, has a slightly higher elevation and trails that tend to dry out more quickly after precipitation events than other areas found on the installation. The major north south tank trail (Route 5) was also sampled in May 2000. These two sampling runs are shown side by side in Figure 4.10. Even though the average PM concentration measured, differed by three orders of magnitude (July 2002 data collected shortly after a rain event had a very low average PM), many of the elevated concentrations shown by red areas are in the same locations in both images. And, again, many of the elevated areas are close to the highway.

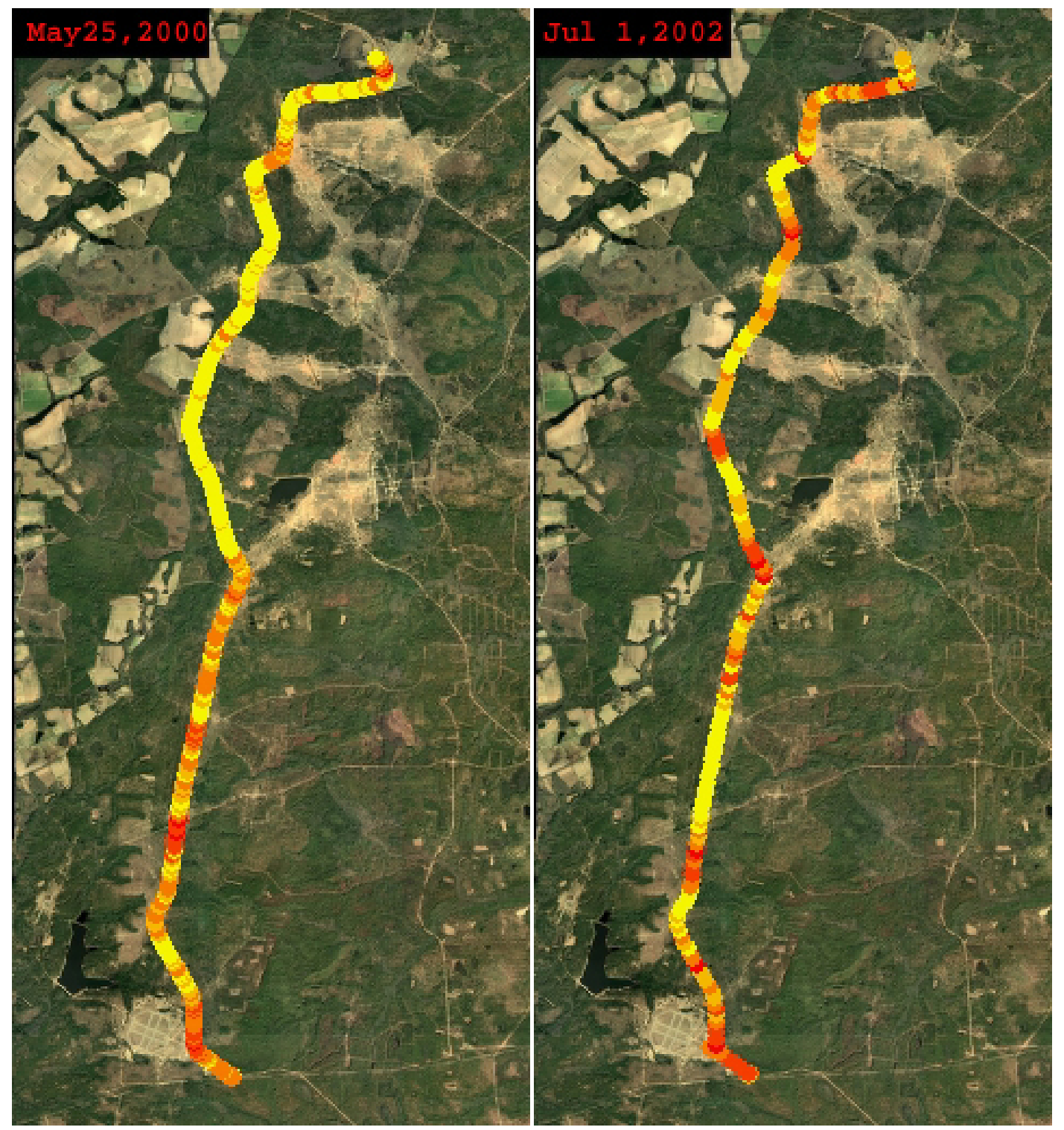

Figure 4.10. May 2000 and July 2002 PM Sampling with MDM. Relative concentration indicated by yellow for low and red for high. (Note the July image would be all yellow if a common stretch were used for both.) 
Road sampling was conducted near cantonment between 4 and 5 pm on May 25, 2000 (Figure 4.10). These values obtained in the late afternoon with increasing $\mathrm{RH}$ are generally lower than the values obtained earlier in the day on the west side of the base (Figure 4.11). There are two areas that standout with elevated PM production the portion of the road near the wetland area in training area D4 and part of the tank trail in training area A-19. The wetlands area probably has higher silt content and is often rougher due to dried ruts in the roadway. The elevated PM found on the tank trail on the northwest boundary of A-19 is probably due to traffic between cantonment and outer training areas via the tank trail that divides A-18 and A-19 heading east.

Fire records were obtained from the Statesboro District of Georgia Forestry Commission (Personal Communication from Dan Gary). A simple linear relationship was developed to convert map grids coordinates to equivalent UTM values. The observed fires and their location are presented in Appendix A (Table A.2).

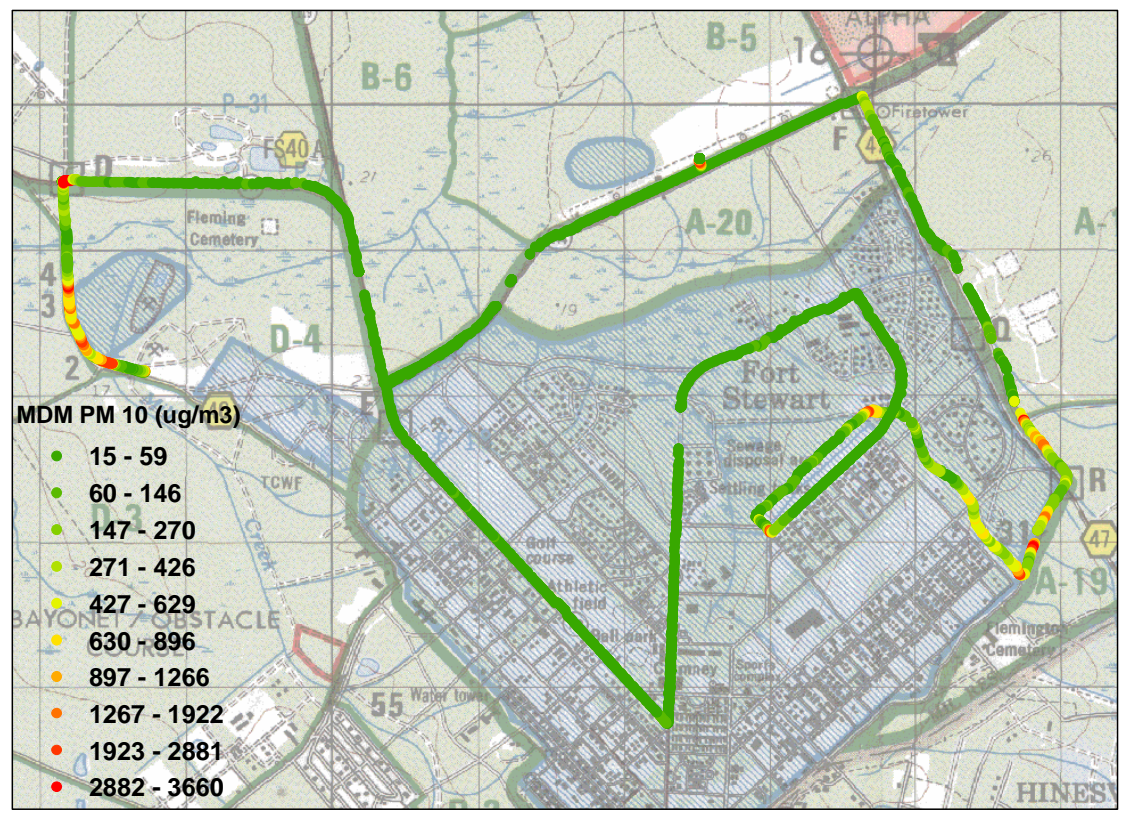

Figure 4.11. Under Vehicle PM10 Measured on May 25, 2000 


\subsection{Conclusions}

The results presented in this report indicate that training at Fort Stewart does not appear to have a significant impact on average PM concentration as compared to PM data collected at nearby Savannah, GA. Under the current PM10 regulations, the installation is in an attainment area. Values for PM2.5 found during this sampling effort indicate that, if proposed PM2.5 regulations are enforced Fort Stewart will likely be in a non-attainment area. It seems that the elevated PM is from regional sources.

There also is an indication that the forest stands present on the installation may actually act to clean the air and improve general air quality. This effect could be very useful when calculating and negotiating pollution credits, especially if the Army is allowed to obtain credit for the removal of PM at one installation and apply it to specific releases at the same or other installations. Further sampling away from towers would be needed to clarify the relationship between forest canopy and air quality on the installation.

The PM emission from tank trails did not appear to be related to soil type, which indicates a GISbased analysis to scale emissions according to soils type will not work at this site. Since the soil map was not a good predictor of release from roadways, the effort to map the installation with the MDM should continue, with emphasis on dry down after major precipitation events. There was a wide range in relative PM production observed with MDM and, as expected, temporal proximity to rainfall events dominated the release. Roadway emissions studies needed to develop AP-42 emission factors were not completed because of rainfall during the scheduled roadway emissions and MDM calibration effort.

Sampling of tank trails does indicate persistence of "hot spots" of elevated PM production even after the trail is wet by recent rains. A full mapping effort would be useful at this site to facilitate dust mitigation efforts on the installation. An effort to identify road segments with high PM for treatment may solve a local dust problem, but have a small effect on the overall PM2.5 concentrations if the installation PM is chemically similar to the eastern United States PM samples, which indicate that geological contributions are a small portion of the PM measured. A chemical analysis of Fort Stewart samples would help to determine if there is a greater fraction of geological materials and might help explain the poor correlation between Savannah and Fort Stewart data.

Some high PM values were measured, but not included in the analyses because they were believed to represent localized sources near the base of the sampling towers. These data suggest that some localized elevated PM production may occur in proximity to the diesel generators operating under camouflage netting.

Other PM-related tasks not funded by Fort Stewart are underway to improve and automate the processing of spatial and temporal data sets collected at FORSCOM installations. The first approach uses GIS-based statistical techniques to determine the footprint of the wind vectors around a sampling point. The number of troops located within this footprint, upwind of the sampling points, can be correlated with corresponding PM measurements. This would allow for a better regression analysis between the troop numbers and PM concentration. A second method involves the use of the GIS-based version of the 
CALPUFF transport model (funded through SERDP) that will allow the user to quickly assign PM sources and look at modeled concentration and compare those to measured values.

Further interaction with the Fort Stewart staff responsible for populating the RFMSS database would help determine the reliability of temporal information such as start and stop times for training areas. The use of RFMSS, GPS vehicle tracking (often referred to as Star Wars data) or directional vehicle counting would greatly enhance the success of either approach. 


\subsection{References}

Draxler RR. 1999. HYSPLIT-4 Users Guide. 1999 NOAA Technical Memorandum ERL ARL-230, National Oceanic and Atmospheric Administration, Washington, D.C.

Lim T-T, AJ Heber, J-Q Ni, JX Gallien, and H Xin. 2003. Air Quality Measurements at a Laying Hen House: Particulate Matter Concentrations and Emissions Air Pollution from Agricultural Operations-III. $3^{\text {rd }}$ International Conference proceedings, The Society for Engineering in Agricultural, Food, and Biological Systems (ASAE), St. Joseph, Michigan.

NOAA, National Environmental Satellite, Data, and Information Service. 2004. Operational Significant Event Imagery. www.osei.noaa.gov/events/Fires/US_Southeast/2002/FSMusGA128_G8.jpg.

U.S. Environmental Protection Agency (USEPA). 1995. Compilation of Air Pollutant Emission Factors. AP-42, Fifth Edition, U.S. Environmental Protection Agency, Research Triangle Park, North Carolina.

U.S. Environmental Protection Agency (USEPA), Office of Air Quality Planning and Standards. Review of National Ambient Air Quality Standards for Particulate Matter: Policy Assessment of Scientific and Technical Information. Report No. EPA-452/R-96-013 (USEPA, Washington, D.C., 1996), pp. V-2$\mathrm{V}-24, \mathrm{~V}-27-\mathrm{V}-28, \mathrm{~V}-71$.

U.S. Environmental Protection Agency (USEPA). 1998. Emission Factor Documentation for AP-42 Section 13.2.2, Unpaved Roads. Final Report. Research Triangle Park, North Carolina.

Vedal S. 1997. “Ambient Particles and Health: Lines That Divide." Journal of the Air and Waste Management Association 47(5):551-81

Yanosky JD and DL MacIntosh. 2001. "A Comparison of Four Gravimetric Fine Particle Sampling Methods." Journal of the Air and Waste Management Association 51:878-884. 


\section{Appendix A}




\section{Appendix A}

Table A.1. MinVol Data

\begin{tabular}{|c|c|c|c|c|c|c|c|c|c|}
\hline $\begin{array}{c}\text { PM2.5 } \mu \mathrm{g} / \mathrm{m}^{3} \\
\text { Elev } 2 \mathrm{~m} . \\
\text { DateRun }\end{array}$ & Glisson & LandSea & Lawson & Pembroke & Richmond & Taylor & Tree & West & Date Avg \\
\hline $7 / 17 / 2000$ & & & 28.8 & & 20.3 & 34.2 & & & 27.7 \\
\hline $7 / 19 / 2000$ & & & 35.7 & 41.1 & 28.9 & 43.0 & & & 37.2 \\
\hline $7 / 22 / 2000$ & 18.5 & & & & 18.7 & 44.8 & & & 27.3 \\
\hline $7 / 24 / 2000$ & 16.6 & & 25.4 & 9.6 & 12.9 & 19.6 & & & 16.8 \\
\hline $7 / 26 / 2000$ & 9.6 & & 8.3 & 8.7 & 11.4 & 13.8 & & & 10.3 \\
\hline $7 / 28 / 2000$ & 19.0 & 6.9 & 8.8 & 8.0 & 10.7 & 18.6 & & & 12.0 \\
\hline $9 / 6 / 2000$ & 5.4 & & 11.3 & 7.1 & 5.6 & 7.4 & & & 7.3 \\
\hline $9 / 8 / 2000$ & 11.0 & & & 9.9 & 6.9 & 4.0 & & & 8.0 \\
\hline $9 / 10 / 2000$ & 13.2 & 5.4 & & & 2.9 & 8.2 & & & 7.4 \\
\hline $9 / 12 / 2000$ & 19.9 & & & 9.7 & 5.7 & 4.6 & & & 10.0 \\
\hline $10 / 8 / 2000$ & & & 10.6 & & & 13.5 & & & 12.0 \\
\hline $10 / 11 / 2000$ & 11.9 & 11.9 & 10.4 & 12.2 & 120.8 & 8.5 & & & 29.3 \\
\hline $10 / 15 / 2000$ & 21.1 & 21.5 & 25.4 & 24.6 & 80.6 & 19.8 & & & 32.2 \\
\hline $10 / 18 / 2000$ & & 25.2 & 17.4 & 26.2 & 82.9 & 21.1 & & & 34.5 \\
\hline $10 / 22 / 2000$ & 18.6 & 14.9 & & 14.8 & 89.7 & & & & 34.5 \\
\hline $10 / 25 / 2000$ & & 28.5 & & 39.6 & & 28.4 & & & 32.2 \\
\hline $10 / 29 / 2000$ & 35.6 & 48.6 & 122.3 & 35.4 & 73.5 & 2.0 & & & 52.9 \\
\hline $11 / 1 / 2000$ & 11.0 & & 13.9 & 2.0 & 27.5 & 48.8 & & & 20.6 \\
\hline $11 / 5 / 2000$ & 8.1 & 14.4 & 11.5 & 2.5 & 2.0 & 3.1 & & & 6.9 \\
\hline $11 / 12 / 2000$ & & & & & 7.0 & 11.1 & & & 9.0 \\
\hline $11 / 18 / 2000$ & 3.4 & & 14.6 & 34.3 & & & & & 17.4 \\
\hline $11 / 24 / 2000$ & 2.0 & 10.4 & 9.2 & & 23.0 & 70.6 & & & 23.0 \\
\hline $11 / 30 / 2000$ & 892.4 & 10.8 & 14.3 & & 8.6 & 33.8 & & & 192.0 \\
\hline $12 / 6 / 2000$ & 20.8 & & 10.3 & 24.1 & 2.8 & 22.8 & & & 16.2 \\
\hline $12 / 12 / 2000$ & & 13.2 & & 11.8 & & 2.0 & & & 9.0 \\
\hline $12 / 18 / 2000$ & 14.0 & & 7.8 & 3.1 & 12.6 & 10.4 & & & 9.6 \\
\hline $12 / 30 / 2000$ & 20.7 & 13.2 & 14.2 & 13.2 & 14.6 & 12.6 & & & 14.7 \\
\hline $1 / 5 / 2001$ & & 23.5 & 10.1 & 13.2 & 8.8 & 7.9 & & & 12.7 \\
\hline $1 / 14 / 2001$ & & & 3.3 & 6.0 & 2.4 & & & & 3.9 \\
\hline $1 / 17 / 2001$ & 4.8 & 8.9 & 2.0 & 4.3 & 3.3 & 2.0 & & & 4.2 \\
\hline $1 / 20 / 2001$ & 2.0 & 2.8 & 15.6 & 7.4 & & 12.9 & & & 8.1 \\
\hline $1 / 23 / 2001$ & & 12.2 & 23.6 & 5.1 & & 9.0 & & & 12.5 \\
\hline $1 / 27 / 2001$ & 14.7 & 2.0 & 9.2 & 13.5 & 2.0 & 2.0 & & & 7.2 \\
\hline $2 / 2 / 2001$ & 2.0 & & 2.0 & 30.0 & 4.3 & 9.4 & & & 9.6 \\
\hline $2 / 5 / 2001$ & 8.9 & 2.0 & 6.1 & 5.3 & & & & & 5.6 \\
\hline $2 / 8 / 2001$ & 20.1 & & 33.2 & 27.1 & & 24.6 & & & 26.2 \\
\hline $2 / 14 / 2001$ & 20.1 & & & 33.5 & & 5.8 & & & 19.8 \\
\hline $2 / 17 / 2001$ & 28.5 & 10.6 & & 47.1 & 5.5 & 2.8 & & & 18.9 \\
\hline $2 / 20 / 2001$ & 24.4 & 3.9 & 8.8 & 26.9 & 2.0 & & & & 13.2 \\
\hline $2 / 26 / 2001$ & 2.6 & & 6.3 & 8.2 & & 21.5 & & & 9.7 \\
\hline $3 / 1 / 2001$ & 44.9 & 5.8 & 29.0 & 35.0 & 3.2 & & & & 23.6 \\
\hline $3 / 4 / 2001$ & 2.0 & 5.1 & 4.4 & 2.0 & 2.0 & 2.0 & & & 2.9 \\
\hline $3 / 7 / 2001$ & 2.4 & 2.0 & 2.0 & 2.0 & & 3.2 & & & 2.3 \\
\hline $3 / 13 / 2001$ & & 7.4 & 9.4 & 7.1 & 4.9 & 16.5 & & & 9.1 \\
\hline $3 / 18 / 2001$ & 2.0 & & 19.0 & 19.9 & 9.5 & 16.8 & & & 13.4 \\
\hline $3 / 20 / 2001$ & & 7.4 & 25.3 & & 23.9 & 2.0 & & & 14.6 \\
\hline $3 / 22 / 2001$ & 14.6 & 13.6 & 15.9 & 10.1 & 3.5 & 2.0 & & 6.8 & 9.5 \\
\hline $3 / 24 / 2001$ & & 8.2 & 2.0 & & 3.1 & 21.9 & 2.0 & 3.2 & 6.7 \\
\hline
\end{tabular}

A. 1 
Table A.1. (contd)

\begin{tabular}{|c|c|c|c|c|c|c|c|c|c|}
\hline $\begin{array}{c}\text { PM2.5 } \mu \mathrm{g} / \mathrm{m}^{3} \\
\text { Elev } 2 \mathrm{~m} . \\
\text { DateRun }\end{array}$ & Glisson & LandSea & Lawson & Pembroke & Richmond & Taylor & Tree & West & Date Avg \\
\hline $3 / 26 / 2001$ & 50.6 & 9.7 & & 17.6 & 17.6 & 39.9 & 18.7 & 21.9 & 25.1 \\
\hline $3 / 30 / 2001$ & 25.8 & 26.0 & 2.0 & 7.7 & 29.0 & 41.7 & 26.1 & 31.5 & 23.7 \\
\hline $4 / 1 / 2001$ & 12.1 & 31.1 & 36.3 & 7.6 & & 26.4 & 27.4 & 9.7 & 21.5 \\
\hline $4 / 5 / 2001$ & 10.7 & 11.3 & 7.1 & 10.1 & 5.3 & 7.1 & 10.0 & 5.6 & 8.4 \\
\hline $4 / 7 / 2001$ & 10.9 & 5.0 & 13.1 & 3.5 & 4.7 & 8.1 & & 33.2 & 11.2 \\
\hline 4/9/2001 & 3.9 & 5.0 & 3.7 & 4.6 & 7.6 & 9.4 & & 12.2 & 6.6 \\
\hline $4 / 11 / 2001$ & 2.0 & & 9.6 & 9.7 & 16.8 & 4.7 & 7.9 & 6.3 & 8.1 \\
\hline $4 / 19 / 2001$ & 6.0 & & 2.8 & 2.4 & 3.8 & 5.8 & 6.1 & & 4.5 \\
\hline $4 / 23 / 2001$ & & 2.8 & & 20.0 & 4.5 & 3.5 & 3.0 & & 6.7 \\
\hline $4 / 25 / 2001$ & 18.5 & & 2.0 & 26.8 & & 5.4 & 3.2 & & 11.2 \\
\hline $6 / 4 / 2001$ & & 14.3 & 7.4 & 9.0 & 6.9 & & 8.6 & 11.5 & 9.6 \\
\hline $6 / 10 / 2001$ & 6.1 & 8.4 & 7.9 & 8.8 & 9.6 & 8.8 & & 7.8 & 8.2 \\
\hline $6 / 14 / 2001$ & & & 10.4 & & & 13.5 & 11.4 & & 11.8 \\
\hline $6 / 16 / 2001$ & 5.1 & 9.2 & 8.9 & 3.8 & 5.1 & 9.1 & 7.4 & 2.0 & 6.3 \\
\hline $6 / 18 / 2001$ & & 17.2 & 5.6 & 16.4 & 4.1 & 3.2 & 4.5 & 3.7 & 7.8 \\
\hline $6 / 22 / 2001$ & 12.9 & 5.0 & 17.9 & & 17.8 & 19.7 & 33.2 & & 17.8 \\
\hline $6 / 26 / 2001$ & 10.4 & 24.2 & 12.0 & 14.4 & 8.3 & & 10.5 & 10.1 & 12.8 \\
\hline $6 / 28 / 2001$ & & 12.4 & & & & & 28.2 & & 20.3 \\
\hline $8 / 2 / 2001$ & 32.4 & & 29.9 & 2.5 & 38.8 & 18.3 & 30.0 & 2.5 & 22.1 \\
\hline $8 / 5 / 2001$ & 43.9 & 4.9 & & 28.8 & 4.3 & 4.6 & 11.1 & 13.9 & 15.9 \\
\hline $8 / 8 / 2001$ & 6.5 & 25.4 & 23.6 & 19.4 & 22.6 & 25.8 & 16.9 & & 20.0 \\
\hline $8 / 11 / 2001$ & 42.1 & 18.9 & 15.1 & 54.0 & 15.9 & 16.8 & 27.4 & 40.6 & 28.9 \\
\hline $8 / 14 / 2001$ & 2.0 & 123.9 & 2.7 & 2.0 & 2.0 & 2.0 & 2.0 & 2.0 & 17.3 \\
\hline $8 / 17 / 2001$ & 2.0 & 2.0 & 2.5 & 2.0 & 2.7 & 4.9 & 9.5 & 7.2 & 4.1 \\
\hline $8 / 23 / 2001$ & 53.8 & 15.9 & 8.2 & 7.2 & 45.7 & 34.9 & 44.6 & 16.6 & 28.3 \\
\hline $8 / 29 / 2001$ & 18.9 & 11.9 & 10.6 & 42.2 & 2.0 & 6.1 & 39.4 & 6.5 & 17.2 \\
\hline $9 / 4 / 2001$ & 2.0 & 2.1 & 2.0 & & & 2.0 & & 7.2 & 3.1 \\
\hline 9/7/2001 & & & & 2.0 & 2.0 & & 2.0 & 8.5 & 3.6 \\
\hline $9 / 10 / 2001$ & 2.0 & 2.0 & 2.0 & 2.0 & 2.0 & 2.0 & 2.0 & 9.9 & 3.0 \\
\hline $9 / 13 / 2001$ & 14.3 & 3.9 & 19.4 & & 17.5 & 2.0 & 16.4 & 23.8 & 13.9 \\
\hline $9 / 19 / 2001$ & & 18.2 & & 13.1 & 26.3 & 22.6 & 14.6 & 15.0 & 18.3 \\
\hline $9 / 22 / 2001$ & 17.6 & 21.5 & 17.4 & 18.8 & 17.4 & 20.4 & 19.3 & 18.5 & 18.9 \\
\hline $9 / 28 / 2001$ & & 23.3 & 22.6 & & & 21.1 & 23.9 & & 22.7 \\
\hline $11 / 9 / 2001$ & 19.7 & & & & & & & & 19.7 \\
\hline $11 / 15 / 2001$ & 19.4 & & & 20.4 & 22.7 & 21.8 & & 13.6 & 19.6 \\
\hline $11 / 27 / 2001$ & & & & & & & 35.8 & & 35.8 \\
\hline $12 / 15 / 2001$ & & & & & & & & 60.0 & 60.0 \\
\hline $1 / 8 / 2002$ & 79.3 & 33.9 & & & & & & & 56.6 \\
\hline $1 / 11 / 2002$ & & & & 28.8 & & & & 3.2 & 16.0 \\
\hline $1 / 20 / 2002$ & 2.0 & & & 2.0 & & & & 2.2 & 2.1 \\
\hline $1 / 23 / 2002$ & & & 17.1 & & 17.6 & & & 16.9 & 17.2 \\
\hline $1 / 29 / 2002$ & & & & & 2.0 & & & 6.9 & 4.5 \\
\hline $2 / 14 / 2002$ & & & & & 28.8 & & & & 28.8 \\
\hline $2 / 16 / 2002$ & 62.1 & 98.8 & 1566.0 & 51.8 & 60.8 & & 36.4 & & 312.6 \\
\hline $2 / 18 / 2002$ & & 19.4 & & & 4.7 & & & & 12.1 \\
\hline $2 / 20 / 2002$ & 2.0 & 2.0 & & & 2.0 & & & 2.0 & 2.0 \\
\hline $2 / 22 / 2002$ & & 2.0 & & & 2.0 & 2.0 & & 2.0 & 2.0 \\
\hline $4 / 11 / 2002$ & 2.0 & & 2.0 & & & & & & 2.0 \\
\hline $4 / 14 / 2002$ & & & & & & & 2.0 & & 2.0 \\
\hline $4 / 20 / 2002$ & & & & & 2.0 & 2.0 & 2.0 & & 2.0 \\
\hline $4 / 26 / 2002$ & 21.5 & & & 6.4 & & & & & 14.0 \\
\hline $5 / 2 / 2002$ & 11.1 & & & & & 2.0 & 2.0 & & 5.0 \\
\hline $5 / 8 / 2002$ & 77.6 & & & 2.0 & & 4.4 & 6.0 & & 22.5 \\
\hline
\end{tabular}


Table A.1. (contd)

\begin{tabular}{|c|c|c|c|c|c|c|c|c|c|}
\hline $\begin{array}{c}\text { PM2.5 } \mu \mathrm{g} / \mathrm{m}^{3} \\
\text { Elev } 2 \mathrm{~m} . \\
\text { DateRun }\end{array}$ & Glisson & LandSea & Lawson & Pembroke & Richmond & Taylor & Tree & West & Date Avg \\
\hline $\begin{array}{l}5 / 14 / 2002 \\
\end{array}$ & 22.8 & & & 11.7 & & & & & 17.2 \\
\hline $5 / 20 / 2002$ & 13.6 & & & & 4.5 & 2.0 & 2.0 & & 5.5 \\
\hline $6 / 1 / 2002$ & 17.8 & & & & 13.7 & & 2.0 & 2.0 & 8.9 \\
\hline $6 / 7 / 2002$ & 2.0 & & & 2.0 & 11.1 & & & & 5.0 \\
\hline $6 / 11 / 2002$ & 5.1 & & 3.8 & 2.0 & 2.0 & 4.7 & & & 3.5 \\
\hline $6 / 13 / 2002$ & 13.8 & & & & & & & & 13.8 \\
\hline $6 / 25 / 2002$ & & & 2.0 & 2.0 & & 3.2 & 2.0 & 2.0 & 2.2 \\
\hline $6 / 27 / 2002$ & 4.4 & & 6.1 & 2.0 & & 11.8 & & 2.0 & 5.3 \\
\hline $6 / 29 / 2002$ & & 25.3 & & 2.0 & & 15.0 & 11.2 & 13.2 & 13.3 \\
\hline $7 / 1 / 2002$ & 14.2 & & 15.1 & 2.0 & 12.8 & 2.5 & 15.7 & 18.8 & 11.6 \\
\hline $7 / 4 / 2002$ & 13.6 & 13.9 & & 2.0 & 11.4 & 14.4 & 13.6 & 13.9 & 11.8 \\
\hline $7 / 7 / 2002$ & & 12.8 & 2.0 & 2.1 & & 13.3 & & & 7.6 \\
\hline $7 / 13 / 2002$ & 10.0 & & & 2.0 & & 11.4 & & 7.9 & 7.8 \\
\hline $7 / 17 / 2002$ & 28.2 & 28.9 & 30.1 & 28.1 & 32.4 & & 20.7 & 30.4 & 28.4 \\
\hline $7 / 19 / 2002$ & 17.3 & 19.4 & 25.0 & 15.7 & 18.5 & 17.7 & 16.1 & 11.7 & 17.7 \\
\hline $7 / 25 / 2002$ & & 11.4 & & & & & 3.4 & & 7.4 \\
\hline $7 / 31 / 2002$ & & & & 10.3 & 9.3 & 15.0 & 12.8 & 2.1 & 9.9 \\
\hline $8 / 3 / 2002$ & & & & 7.6 & 6.2 & & 6.1 & & 6.7 \\
\hline $8 / 6 / 2002$ & & 24.5 & & 21.0 & 20.1 & & 19.9 & & 21.4 \\
\hline $8 / 12 / 2002$ & & & & & & & & 2.5 & 2.5 \\
\hline $8 / 18 / 2002$ & 8.1 & & 9.4 & 9.4 & 7.6 & 9.1 & 8.9 & 2.0 & 7.8 \\
\hline $8 / 19 / 2002$ & & 6.9 & 7.5 & 8.8 & 9.9 & 6.5 & 9.0 & 2.2 & 7.3 \\
\hline $10 / 24 / 2002$ & & 11.9 & 12.2 & 11.9 & 11.5 & 11.7 & 9.5 & 11.0 & 11.4 \\
\hline $10 / 27 / 2002$ & & 11.8 & 12.5 & 18.7 & 15.4 & 15.5 & 11.8 & & 14.3 \\
\hline $10 / 29 / 2002$ & 4.5 & 8.4 & & & 9.2 & & & & 7.4 \\
\hline $10 / 31 / 2002$ & 10.5 & 11.8 & 7.3 & 8.8 & 12.2 & 8.3 & 14.9 & 10.0 & 10.5 \\
\hline $11 / 4 / 2002$ & 10.7 & & 11.5 & 8.2 & 10.6 & 14.2 & & 13.0 & 11.4 \\
\hline $11 / 10 / 2002$ & 9.5 & 9.9 & 7.2 & 7.6 & 2.9 & 7.6 & & & 7.5 \\
\hline Site Avg & 26.2 & 15.7 & 32.5 & 13.8 & 15.8 & 13.6 & 13.8 & 11.6 & 18.3 \\
\hline
\end{tabular}

\begin{tabular}{|c|c|c|c|c|c|c|c|c|}
\hline $\begin{array}{c}\text { PM2.5 } \mu \mathrm{g} / \mathrm{m}^{3} \\
\text { Elev } 10 \mathrm{~m} . \\
\text { DateRun }\end{array}$ & Glisson & Lawson & Pembroke & Richmond & Taylor & Tree & West & Date Avg \\
\hline$\overline{c 7 / 17 / 2000}$ & & 21.3 & & 26.1 & 44.1 & & & 30.5 \\
\hline $7 / 19 / 2000$ & 85.9 & & 50.1 & 38.8 & & & & 58.3 \\
\hline $7 / 22 / 2000$ & & 23.4 & 25.8 & 17.2 & 21.0 & & & 21.8 \\
\hline $7 / 24 / 2000$ & 11.9 & 8.1 & & 8.7 & 9.8 & & & 9.6 \\
\hline $7 / 26 / 2000$ & 11.5 & 16.4 & 11.2 & 12.8 & 27.6 & & & 15.9 \\
\hline $7 / 28 / 2000$ & 15.0 & 15.3 & 10.5 & 8.9 & 6.9 & & & 11.3 \\
\hline $9 / 6 / 2000$ & 8.6 & & 6.6 & & & & & 7.6 \\
\hline $9 / 8 / 2000$ & & & 3.1 & 7.5 & & & & 5.3 \\
\hline $9 / 10 / 2000$ & & & & 4.6 & 5.8 & & & 5.2 \\
\hline $9 / 12 / 2000$ & & & & 6.3 & 4.4 & & & 5.4 \\
\hline $10 / 8 / 2000$ & 12.5 & 14.0 & & 9.6 & 7.2 & & & 10.8 \\
\hline $10 / 11 / 2000$ & & & 17.1 & 87.9 & 11.2 & & & 38.7 \\
\hline $10 / 15 / 2000$ & 22.6 & 27.9 & & 56.7 & 26.0 & & & 33.3 \\
\hline $10 / 18 / 2000$ & 23.4 & 27.5 & & & 27.3 & & & 26.0 \\
\hline $10 / 22 / 2000$ & 17.1 & 51.9 & & 17.4 & 15.3 & & & 25.4 \\
\hline $10 / 25 / 2000$ & & & 31.4 & & 30.7 & & & 31.0 \\
\hline $10 / 29 / 2000$ & 23.0 & 175.2 & 111.4 & 81.5 & 27.8 & & & 83.8 \\
\hline $11 / 1 / 2000$ & 10.6 & 23.1 & 2.0 & 31.0 & 107.6 & & & 34.9 \\
\hline
\end{tabular}


Table A.1. (contd)

\begin{tabular}{|c|c|c|c|c|c|c|c|c|}
\hline $\begin{array}{c}\text { PM2.5 } \mu \mathrm{g} / \mathrm{m}^{3} \\
\text { Elev } 10 \mathrm{~m} . \\
\text { DateRun }\end{array}$ & Glisson & Lawson & Pembroke & Richmond & Taylor & Tree & West & Date Avg \\
\hline $211 / 5 / 2000$ & 9.9 & 111.7 & 2.0 & 9.6 & 7.2 & & & 8.1 \\
\hline $11 / 12 / 2000$ & & & & 10.7 & 13.6 & & & 12.2 \\
\hline $11 / 18 / 2000$ & 7.5 & 2.0 & 48.0 & & & & & 19.2 \\
\hline $11 / 24 / 2000$ & 8.8 & 22.3 & & 26.5 & 65.1 & & & 30.7 \\
\hline $11 / 30 / 2000$ & 963.5 & 16.5 & & 8.9 & 13.8 & & & 250.7 \\
\hline $12 / 6 / 2000$ & 6.8 & 12.6 & 25.7 & 2.8 & 27.4 & & & 15.1 \\
\hline $12 / 12 / 2000$ & 9.9 & 12.8 & 14.3 & & & & & 12.3 \\
\hline $12 / 18 / 2000$ & 13.6 & 4.3 & 5.3 & 4.7 & 9.9 & & & 7.6 \\
\hline $12 / 30 / 2000$ & 14.9 & 14.7 & 15.4 & 16.5 & 16.0 & & & 15.5 \\
\hline $1 / 5 / 2001$ & & 11.8 & 12.2 & 9.0 & 11.4 & & & 11.1 \\
\hline $1 / 14 / 2001$ & & 4.3 & & 2.6 & & & & 3.5 \\
\hline $1 / 17 / 2001$ & 2.0 & 9.6 & 3.8 & 5.6 & 34.7 & & & 11.1 \\
\hline $1 / 20 / 2001$ & 15.6 & 43.2 & 11.7 & & 14.6 & & & 21.3 \\
\hline $1 / 23 / 2001$ & 9.7 & 12.1 & 4.9 & 6.3 & 9.8 & & & 8.5 \\
\hline $1 / 27 / 2001$ & 18.2 & 3.5 & 20.6 & 3.3 & 2.0 & & & 9.5 \\
\hline $2 / 2 / 2001$ & 2.0 & 2.0 & 27.5 & 3.3 & 26.4 & & & 12.2 \\
\hline $2 / 5 / 2001$ & & 2.0 & 7.1 & & & & & 4.5 \\
\hline $2 / 8 / 2001$ & 14.4 & 30.8 & 15.7 & & 26.7 & & & 21.9 \\
\hline $2 / 14 / 2001$ & 33.9 & & 55.4 & & 12.2 & & & 33.8 \\
\hline $2 / 17 / 2001$ & 22.8 & 21.1 & 26.1 & 5.4 & 2.0 & & & 15.5 \\
\hline $2 / 20 / 2001$ & 13.3 & 9.9 & 29.6 & & & & & 17.6 \\
\hline $2 / 26 / 2001$ & 4.4 & 7.6 & 3.5 & & 16.0 & & & 7.9 \\
\hline $3 / 1 / 2001$ & 43.1 & 39.6 & 39.4 & 2.0 & & & & 31.0 \\
\hline $3 / 4 / 2001$ & 2.0 & 2.2 & 2.0 & 2.0 & 2.0 & & & 2.0 \\
\hline 3/7/2001 & & 2.0 & 2.0 & 2.0 & 2.0 & & & 2.0 \\
\hline $3 / 13 / 2001$ & & 14.4 & 5.5 & 9.3 & & & & 9.8 \\
\hline $3 / 18 / 2001$ & 5.1 & 11.8 & 19.4 & 14.9 & 15.0 & & & 13.2 \\
\hline $3 / 20 / 2001$ & & 21.5 & & 8.2 & 2.0 & & & 10.6 \\
\hline $3 / 22 / 2001$ & 8.8 & 53.1 & 19.9 & 3.9 & 4.2 & & 12.9 & 17.1 \\
\hline $3 / 24 / 2001$ & & 2.4 & & 2.0 & 18.2 & 5.4 & 55.4 & 16.7 \\
\hline $3 / 26 / 2001$ & & & 36.5 & 28.8 & 44.7 & 36.3 & 6.5 & 30.5 \\
\hline $3 / 30 / 2001$ & 32.1 & & 31.7 & 34.2 & 26.4 & 33.2 & 32.9 & 31.7 \\
\hline $4 / 1 / 2001$ & 12.6 & 34.7 & 7.4 & 34.1 & 28.2 & 82.5 & 23.6 & 31.9 \\
\hline $4 / 5 / 2001$ & 10.0 & 6.7 & 6.1 & 10.0 & 4.9 & 10.0 & 8.6 & 8.0 \\
\hline $4 / 7 / 2001$ & 5.0 & 6.6 & 4.9 & 2.0 & & & 12.2 & 6.1 \\
\hline $4 / 9 / 2001$ & & 2.0 & 8.5 & 7.9 & 11.7 & 2.0 & 7.2 & 6.5 \\
\hline $4 / 11 / 2001$ & 2.2 & 14.0 & 2.9 & 6.1 & 13.5 & 15.8 & 7.2 & 8.8 \\
\hline $4 / 19 / 2001$ & 5.3 & 7.2 & 2.0 & 6.0 & 3.9 & 5.6 & & 5.0 \\
\hline $4 / 23 / 2001$ & 2.0 & 2.0 & 4.7 & 2.0 & 2.9 & 4.0 & & 2.9 \\
\hline $4 / 25 / 2001$ & 10.1 & 3.8 & 11.9 & & 2.8 & 23.2 & & 10.4 \\
\hline $6 / 4 / 2001$ & 5.8 & 9.7 & 9.0 & 8.1 & & 8.9 & 7.0 & 8.1 \\
\hline $6 / 10 / 2001$ & 9.4 & 8.1 & 9.7 & 10.5 & 7.4 & 7.5 & 8.5 & 8.7 \\
\hline $6 / 14 / 2001$ & & 11.0 & & & 11.1 & 9.9 & 11.1 & 10.8 \\
\hline $6 / 16 / 2001$ & 2.0 & 4.4 & 4.1 & 4.8 & 2.0 & 14.6 & 65.2 & 13.9 \\
\hline $6 / 18 / 2001$ & 17.1 & 3.4 & 15.3 & 8.3 & 4.3 & 20.3 & 8.8 & 11.1 \\
\hline $6 / 22 / 2001$ & 6.1 & 18.6 & 22.3 & 4.2 & 17.7 & 11.9 & 17.6 & 14.1 \\
\hline $6 / 26 / 2001$ & 9.8 & 9.8 & 6.5 & & 10.7 & 11.1 & 10.8 & 9.8 \\
\hline $6 / 28 / 2001$ & & 39.7 & & & 17.4 & 41.8 & & 33.0 \\
\hline $8 / 2 / 2001$ & 30.6 & 36.2 & 27.2 & 4.1 & 41.5 & 9.0 & 4.1 & 21.8 \\
\hline $8 / 5 / 2001$ & 4.3 & 3.5 & 2.0 & 2.9 & 2.0 & 10.8 & 18.1 & 6.2 \\
\hline $8 / 8 / 2001$ & 11.8 & 25.3 & 44.3 & 20.4 & 25.9 & 14.4 & 20.3 & 23.2 \\
\hline $8 / 11 / 2001$ & 95.0 & 17.6 & 36.1 & 29.9 & 14.0 & 86.1 & 38.7 & 45.3 \\
\hline $8 / 14 / 2001$ & 3.2 & 5.3 & 2.0 & 2.0 & 2.0 & 2.0 & 2.0 & 2.6 \\
\hline
\end{tabular}


Table A.1. (contd)

\begin{tabular}{|c|c|c|c|c|c|c|c|c|}
\hline $\begin{array}{c}\text { PM2.5 } \mu \mathrm{g} / \mathrm{m}^{3} \\
\text { Elev } 10 \mathrm{~m} . \\
\text { DateRun }\end{array}$ & Glisson & Lawson & Pembroke & Richmond & Taylor & Tree & West & Date Avg \\
\hline $8 / 17 / 2001$ & 10.8 & 2.2 & 13.4 & 3.2 & 2.0 & 2.0 & 36.4 & 10.0 \\
\hline $8 / 23 / 2001$ & 10.6 & 11.0 & 91.3 & 3.4 & 40.3 & 29.0 & 40.4 & 32.3 \\
\hline $8 / 29 / 2001$ & 16.2 & 8.9 & 18.3 & 71.0 & 58.3 & 11.3 & 17.5 & 28.8 \\
\hline $9 / 4 / 2001$ & 2.6 & & 5.3 & 2.0 & 2.0 & 2.0 & 21.8 & 5.9 \\
\hline 9/7/2001 & 2.0 & & 2.0 & 2.0 & & 6.4 & 2.0 & 2.9 \\
\hline $9 / 10 / 2001$ & 2.0 & 2.0 & 2.0 & 4.2 & & 2.0 & 2.0 & 2.4 \\
\hline 9/13/2001 & 27.5 & 20.6 & 15.3 & 15.7 & 27.9 & 14.6 & 20.1 & 20.2 \\
\hline 9/19/2001 & & 26.8 & 16.1 & & 44.2 & 19.7 & & 26.7 \\
\hline 9/22/2001 & 15.4 & 18.1 & 15.1 & 25.3 & 34.9 & 17.1 & 17.2 & 20.4 \\
\hline 9/28/2001 & 18.6 & 19.7 & 21.7 & & & & 23.8 & 21.0 \\
\hline 11/9/2001 & & 24.4 & & 13.6 & 19.6 & & 49.4 & 26.7 \\
\hline $11 / 15 / 2001$ & 13.3 & & & 21.5 & & 21.7 & 18.6 & 18.8 \\
\hline $11 / 27 / 2001$ & & & & 14.3 & 20.6 & 14.6 & & 16.5 \\
\hline $1 / 8 / 2002$ & 44.9 & & & & 22.2 & & & 33.5 \\
\hline $1 / 11 / 2002$ & & & & & & & 12.9 & 12.9 \\
\hline $1 / 14 / 2002$ & & 2.0 & 2.0 & & & & & 2.0 \\
\hline $1 / 20 / 2002$ & 2.0 & & & & & & 2.0 & 2.0 \\
\hline $1 / 23 / 2002$ & & 14.7 & & & & & & 14.7 \\
\hline $1 / 29 / 2002$ & & & 2.2 & & 2.0 & & 5.0 & 3.1 \\
\hline $2 / 16 / 2002$ & 24.9 & & 27.1 & 50.7 & & 47.9 & & 37.6 \\
\hline $2 / 18 / 2002$ & & & & 5.5 & & & & 5.5 \\
\hline $2 / 20 / 2002$ & 2.0 & & 2.0 & 2.0 & & & 11.3 & 4.3 \\
\hline $2 / 22 / 2002$ & & & & 2.0 & 11.3 & & 2.0 & 5.1 \\
\hline $4 / 11 / 2002$ & & & & 2.0 & & & & 2.0 \\
\hline $4 / 14 / 2002$ & & & & 2.0 & 2.0 & 2.0 & & 2.0 \\
\hline $4 / 20 / 2002$ & 2.0 & & & 2.0 & 2.0 & & & 2.0 \\
\hline $6 / 27 / 2002$ & 9.7 & 12.9 & 2.0 & & 14.3 & & & 9.7 \\
\hline $6 / 29 / 2002$ & 15.3 & 12.9 & 2.9 & 11.4 & 14.0 & 14.6 & & 11.9 \\
\hline $7 / 1 / 2002$ & & 14.6 & 2.0 & & & 2.0 & 16.7 & 8.8 \\
\hline $7 / 4 / 2002$ & 13.3 & 14.0 & 2.0 & 11.9 & 15.6 & 15.8 & 14.2 & 12.4 \\
\hline $7 / 7 / 2002$ & 3.2 & & 2.0 & 3.1 & 13.3 & 11.9 & 14.9 & 8.1 \\
\hline $7 / 13 / 2002$ & 10.8 & & 2.0 & 11.3 & 11.7 & 9.3 & 12.9 & 9.7 \\
\hline $7 / 17 / 2002$ & 29.4 & 32.2 & & 33.7 & 26.8 & & 28.1 & 30.0 \\
\hline 7/19/2002 & 18.2 & 20.6 & & 17.5 & 2.0 & 15.7 & & 14.8 \\
\hline $7 / 25 / 2002$ & 7.6 & 8.3 & 2.0 & 6.9 & 13.5 & & 4.0 & 7.1 \\
\hline $7 / 31 / 2002$ & 10.0 & & 2.0 & 12.0 & & 12.1 & & 9.0 \\
\hline $8 / 3 / 2002$ & & & 2.0 & & & 10.9 & 8.5 & 7.1 \\
\hline $8 / 6 / 2002$ & 22.6 & & 2.4 & 18.6 & & 21.4 & & 16.3 \\
\hline $8 / 12 / 2002$ & 12.7 & 7.6 & & 2.8 & 2.0 & 4.3 & & 5.9 \\
\hline $8 / 18 / 2002$ & & & & 7.8 & 2.0 & 9.2 & & 6.3 \\
\hline 8/19/2002 & 2.0 & & 2.0 & & 7.3 & 6.4 & & 4.4 \\
\hline $10 / 24 / 2002$ & 8.1 & & 3.6 & & 9.6 & & & 7.1 \\
\hline $10 / 27 / 2002$ & 13.2 & & 12.7 & 14.8 & 12.8 & 12.9 & & 13.3 \\
\hline $10 / 29 / 2002$ & 7.1 & 7.6 & & & & & 6.7 & 7.1 \\
\hline $10 / 31 / 2002$ & 10.7 & 8.1 & 10.5 & 8.8 & 8.4 & 16.5 & 10.4 & 10.4 \\
\hline $11 / 4 / 2002$ & & 2.0 & 10.7 & 9.1 & & 4.1 & 13.8 & 7.9 \\
\hline $11 / 10 / 2002$ & 3.1 & 4.8 & 8.5 & 5.0 & 13.0 & & & 6.9 \\
\hline Grand Total & 25.5 & 16.5 & 15.1 & 13.7 & 16.8 & 16.1 & 16.8 & 17.3 \\
\hline
\end{tabular}


Table A.2. Offsite Fire Data Recorded by the Statesboro District of Georgia Forestry Commission, UTM Coordinates Estimated

\begin{tabular}{|c|c|c|c|c|c|}
\hline Date & Fire Type & Acres & Location & $\overline{\mathrm{X}}$ & 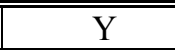 \\
\hline $10 / 11 / 2000$ & "27 small leaf piles" & & "CA?" & 560000.00 & 3570000.00 \\
\hline $10 / 11 / 2000$ & "1 land clearing" & 2.00 & "CQ85" & 414329.00 & 3536016.00 \\
\hline $10 / 11 / 2000$ & "1 hazard reduction" & 1.00 & "CP82" & 408668.00 & 3534118.00 \\
\hline $10 / 11 / 2000$ & "2 cultivated crop" & 22.00 & "CN85 CM84" & 414329.00 & 3530322.00 \\
\hline $10 / 11 / 2000$ & "Land clearing " & 5.00 & “CH 92” & 427538.00 & 3518934.00 \\
\hline $10 / 11 / 2000$ & "Site Prep" & 60.00 & "CH88” & 419990.00 & 3518934.00 \\
\hline $10 / 29 / 2000$ & "no wildfires no Significant control burns " & & & 560000.00 & 3570000.00 \\
\hline $11 / 30 / 2000$ & "no wildfires" & & & 560000.00 & 3570000.00 \\
\hline $11 / 30 / 2000$ & "29 Small leaf piles" & & & 560000.00 & 3570000.00 \\
\hline $11 / 30 / 2000$ & "1 old fields" & 10.00 & "CU84" & 412442.00 & 3543608.00 \\
\hline $11 / 30 / 2000$ & "Land clearing" & 25.00 & "CN84" & 412442.00 & 3530322.00 \\
\hline $11 / 30 / 2000$ & "Land clearing" & 2.00 & "DB77" & 399233.00 & 3556894.00 \\
\hline $11 / 30 / 2000$ & "Land clearing" & 4.00 & "DE79" & 403007.00 & 3562588.00 \\
\hline $11 / 30 / 2000$ & "Field" & 5.00 & "CJ87 SW" & 418103.00 & 3522730.00 \\
\hline $11 / 30 / 2000$ & "Pasture" & 30.00 & "CG96 SW" & 435086.00 & 3517036.00 \\
\hline $11 / 30 / 2000$ & "landclearing" & 4.00 & "CL87 NE" & 418103.00 & 3526526.00 \\
\hline $11 / 30 / 2000$ & "Site Prep" & 20.00 & "BX103 NE" & 448295.00 & 3499954.00 \\
\hline $11 / 30 / 2000$ & "Site Prep" & 25.00 & "CB92 SW" & 427538.00 & 3507546.00 \\
\hline $3 / 1 / 2001$ & "fire \# 57 " & 5.44 & $\begin{array}{l}\text { "UTM E03903 } \\
\text { N35452" }\end{array}$ & 390300.00 & 3570000.00 \\
\hline $3 / 1 / 2001$ & "Pasture" & 10.00 & "CV75" & 395459.00 & 3545506.00 \\
\hline $3 / 1 / 2001$ & "Pasture" & 150.00 & "CT72" & 389798.00 & 3541710.00 \\
\hline $3 / 1 / 2001$ & "Pasture" & 1.00 & "DG79" & 403007.00 & 3566384.00 \\
\hline $3 / 1 / 2001$ & "Cultivated crop" & 8.00 & "DD73" & 391685.00 & 3560690.00 \\
\hline $3 / 1 / 2001$ & "Field" & 3.00 & "CT77" & 399233.00 & 3541710.00 \\
\hline $3 / 1 / 2001$ & "Field" & 15.00 & $\begin{array}{l}\text { "UTM E4830 } \\
\text { N35650" }\end{array}$ & 483000.00 & 3565000.00 \\
\hline $3 / 1 / 2001$ & "Pasture" & 50.00 & $\begin{array}{l}\text { "UTM E4823 } \\
\text { N35420" }\end{array}$ & 482300.00 & 3542000.00 \\
\hline $3 / 1 / 2001$ & "Understory" & 20.00 & $\begin{array}{l}\text { "UTM E4731 } \\
\text { N35380" }\end{array}$ & 473100.00 & 3538000.00 \\
\hline $3 / 1 / 2001$ & "Understory" & 10.00 & $\begin{array}{l}\text { "UTM E4700 } \\
\text { N35420" }\end{array}$ & 470000.00 & 3542000.00 \\
\hline $3 / 22 / 2001$ & "no wildfires or significant controlled burns" & & & 560000.00 & 3570000.00 \\
\hline $3 / 22 / 2001$ & & & & 560000.00 & 3570000.00 \\
\hline $3 / 26 / 2001$ & "no wildfires “ & & & 560000.00 & 3570000.00 \\
\hline $3 / 26 / 2001$ & "Field" & 1.00 & "CK93 NW" & 429425.00 & 3524628.00 \\
\hline $3 / 26 / 2001$ & & & & 560000.00 & 3570000.00 \\
\hline $4 / 1 / 2001$ & "fire \# 68“ & 12.70 & $\begin{array}{l}\text { "UTM E03859 } \\
\text { W35551" }\end{array}$ & 385900.00 & 3570000.00 \\
\hline $4 / 1 / 2001$ & "Wildfire" & 171.00 & "CA94 SE" & 431312.00 & 3505648.00 \\
\hline $4 / 1 / 2001$ & "Wildfire" & 3.56 & "CE98 NE" & 438860.00 & 3513240.00 \\
\hline $4 / 1 / 2001$ & "no control burns" & & & 560000.00 & 3570000.00 \\
\hline $6 / 20 / 2001$ & "fire \# 86 " & 0.01 & $\begin{array}{l}\text { "E03940 } \\
\text { W35401" }\end{array}$ & 394000.00 & 3570000.00 \\
\hline $6 / 20 / 2001$ & "2 leaf piles" & & & 560000.00 & 3570000.00 \\
\hline
\end{tabular}


Table A.2. (contd)

\begin{tabular}{|c|c|c|c|c|c|}
\hline Date & Fire Type & Acres & Location & $\bar{X}$ & $\overline{\mathrm{Y}}$ \\
\hline 6/20/2001 & "Landclearing" & 1.00 & "CJ88 SW" & 419990.00 & 3522730.00 \\
\hline $6 / 20 / 2001$ & "Cultivated crop land" & 75.00 & "CU85" & 414329.00 & 3543608.00 \\
\hline $6 / 20 / 2001$ & "Field" & 10.00 & "DE78" & 401120.00 & 3562588.00 \\
\hline $6 / 20 / 2001$ & "Field" & 35.00 & "DF76" & 397346.00 & 3564486.00 \\
\hline $6 / 20 / 2001$ & & & & 560000.00 & 3570000.00 \\
\hline $6 / 28 / 2001$ & "Wildfire" & 0.13 & “CD97 SE” & 436973.00 & 3511342.00 \\
\hline $6 / 28 / 2001$ & "Wildfire" & 0.18 & "CD98 SE" & 438860.00 & 3511342.00 \\
\hline $6 / 28 / 2001$ & "3 leaf piles" & & & 560000.00 & 3570000.00 \\
\hline $8 / 2 / 2001$ & "no wildfires" & & & 560000.00 & 3570000.00 \\
\hline $8 / 2 / 2001$ & "2 leaf piles" & & & 560000.00 & 3570000.00 \\
\hline $8 / 2 / 2001$ & "1 land clearing" & 1.00 & "DA77" & 399233.00 & 3554996.00 \\
\hline $8 / 11 / 2001$ & "Wildfire" & 0.71 & "CD97 NW" & 436973.00 & 3511342.00 \\
\hline $8 / 11 / 2001$ & "8 leaf pile" & & & 560000.00 & 3570000.00 \\
\hline $8 / 11 / 2001$ & & & & 560000.00 & 3570000.00 \\
\hline $8 / 29 / 2001$ & "no wildfires" & & & 560000.00 & 3570000.00 \\
\hline $8 / 29 / 2001$ & "17 leaf piles" & & & 560000.00 & 3570000.00 \\
\hline $8 / 29 / 2001$ & "Site Prep" & 60.00 & "CC91" & 425651.00 & 3509444.00 \\
\hline $9 / 19 / 2001$ & "No significant Wildfires " & & & 560000.00 & 3570000.00 \\
\hline 9/19/2001 & “21 leaf piles" & & & 560000.00 & 3570000.00 \\
\hline 9/19/2001 & "1 land clearing" & 27.00 & "CN77" & 399233.00 & 3530322.00 \\
\hline $11 / 9 / 2001$ & "no wildfires" & & & 560000.00 & 3570000.00 \\
\hline $11 / 9 / 2001$ & “12 leaf piles" & & & 560000.00 & 3570000.00 \\
\hline $1 / 8 / 2002$ & "no wildfires" & & & 560000.00 & 3570000.00 \\
\hline $1 / 8 / 2002$ & "Landclearing" & 10.00 & "CF96 SW" & 435086.00 & 3515138.00 \\
\hline $1 / 8 / 2002$ & “6 leaf piles" & & & 560000.00 & 3570000.00 \\
\hline $1 / 8 / 2002$ & "1 Cultivated crop " & 5.00 & "DJ70" & 386024.00 & 3572078.00 \\
\hline $1 / 8 / 2002$ & "1 land clearing" & 1.00 & "CZ80" & 404894.00 & 3553098.00 \\
\hline $2 / 16 / 2002$ & "Wildfire" & 0.15 & $\begin{array}{l}\text { "E03940 } \\
\text { W35458" }\end{array}$ & 394000.00 & 3570000.00 \\
\hline $2 / 16 / 2002$ & "33 leaf piles" & & & 560000.00 & 3570000.00 \\
\hline $2 / 16 / 2002$ & "Field" & 4.00 & "BX 100 SE" & 442634.00 & 3499954.00 \\
\hline $2 / 16 / 2002$ & "Field" & 5.00 & “CJ87 SE” & 418103.00 & 3522730.00 \\
\hline $2 / 16 / 2002$ & "Field" & 1.00 & "CI85 SE" & 414329.00 & 3520832.00 \\
\hline $2 / 16 / 2002$ & "Field" & 7.00 & "CK92 NE" & 427538.00 & 3524628.00 \\
\hline $2 / 16 / 2002$ & "Field" & 1.00 & "CJ90 SE" & 423764.00 & 3522730.00 \\
\hline $2 / 16 / 2002$ & "Improved pasture " & 20.00 & “CZ75 “" & 395459.00 & 3553098.00 \\
\hline $2 / 16 / 2002$ & "Improved pasture " & 25.00 & "DB80" & 404894.00 & 3556894.00 \\
\hline $2 / 16 / 2002$ & "cultivated crop" & 20.00 & "CX77" & 399233.00 & 3549302.00 \\
\hline $2 / 16 / 2002$ & "Understory Burn" & 30.00 & "CU82" & 408668.00 & 3543608.00 \\
\hline $7 / 17 / 2002$ & "no wildfires" & & & 560000.00 & 3570000.00 \\
\hline $7 / 17 / 2002$ & “18 leaf piles" & & & 560000.00 & 3570000.00 \\
\hline
\end{tabular}


Table A.3. TEOM Data $\mu \mathrm{g} / \mathrm{m}^{3}$ (24 hour ave) Collected at SHED Site Fort Stewart, Georgia

\begin{tabular}{|c|c|}
\hline Date & TEOM_PM10 \\
\hline $8 / 13 / 2000$ & 12.3 \\
\hline $8 / 14 / 2000$ & 13.65 \\
\hline $8 / 15 / 2000$ & 14.07 \\
\hline $8 / 16 / 2000$ & 12.93 \\
\hline $8 / 17 / 2000$ & 23.58 \\
\hline $8 / 18 / 2000$ & 15.05 \\
\hline $8 / 19 / 2000$ & 9.56 \\
\hline $8 / 20 / 2000$ & 6.59 \\
\hline $8 / 21 / 2000$ & 13.58 \\
\hline $8 / 22 / 2000$ & 24.14 \\
\hline $9 / 11 / 2000$ & 18.88 \\
\hline $9 / 12 / 2000$ & 16.18 \\
\hline $9 / 13 / 2000$ & 21.5 \\
\hline $9 / 14 / 2000$ & 26.41 \\
\hline $9 / 15 / 2000$ & 32.3 \\
\hline $9 / 16 / 2000$ & 21.09 \\
\hline $9 / 17 / 2000$ & 16.32 \\
\hline $9 / 18 / 2000$ & 10.25 \\
\hline $9 / 19 / 2000$ & 20.82 \\
\hline $9 / 20 / 2000$ & 22.01 \\
\hline $9 / 21 / 2000$ & 25.44 \\
\hline $9 / 22 / 2000$ & 15.4 \\
\hline $9 / 23 / 2000$ & 15.93 \\
\hline $9 / 24 / 2000$ & 17.22 \\
\hline $9 / 25 / 2000$ & 18.34 \\
\hline $9 / 26 / 2000$ & 6.35 \\
\hline $9 / 27 / 2000$ & 11.6 \\
\hline $9 / 28 / 2000$ & 11.21 \\
\hline $9 / 29 / 2000$ & 22.35 \\
\hline $9 / 30 / 2000$ & 18.31 \\
\hline $10 / 1 / 2000$ & 8.93 \\
\hline $10 / 2 / 2000$ & 13.16 \\
\hline $10 / 3 / 2000$ & 14.69 \\
\hline $10 / 4 / 2000$ & 10.75 \\
\hline $10 / 5 / 2000$ & 8.78 \\
\hline $12 / 11 / 2000$ & 23.96 \\
\hline $12 / 14 / 2000$ & 23.84 \\
\hline $2 / 4 / 2001$ & 17.46 \\
\hline $2 / 5 / 2001$ & 8.89 \\
\hline $2 / 6 / 2001$ & 12.7 \\
\hline $2 / 7 / 2001$ & 26.7 \\
\hline $2 / 8 / 2001$ & 24.82 \\
\hline $2 / 9 / 2001$ & 18.92 \\
\hline $2 / 10 / 2001$ & 12.8 \\
\hline $2 / 11 / 2001$ & 16.25 \\
\hline $2 / 12 / 2001$ & 12.69 \\
\hline $2 / 13 / 2001$ & 10.66 \\
\hline $2 / 14 / 2001$ & 14.68 \\
\hline $2 / 15 / 2001$ & 14.8 \\
\hline $2 / 16 / 2001$ & 12.3 \\
\hline
\end{tabular}

\begin{tabular}{|l|c|}
\hline \multicolumn{1}{|c|}{ Date } & TEOM_PM10 \\
\hline $2 / 17 / 2001$ & 7.2 \\
\hline $2 / 18 / 2001$ & 11.54 \\
\hline $2 / 19 / 2001$ & 19.92 \\
\hline $2 / 20 / 2001$ & 20.23 \\
\hline $2 / 21 / 2001$ & 30.2 \\
\hline $2 / 22 / 2001$ & 22.84 \\
\hline $2 / 23 / 2001$ & 16.25 \\
\hline $2 / 24 / 2001$ & 16.21 \\
\hline $2 / 25 / 2001$ & 14.73 \\
\hline $2 / 26 / 2001$ & 15.25 \\
\hline $2 / 27 / 2001$ & 21.62 \\
\hline $2 / 28 / 2001$ & 20.25 \\
\hline $3 / 1 / 2001$ & 16.22 \\
\hline $3 / 2 / 2001$ & 24.7 \\
\hline $3 / 3 / 2001$ & 13.38 \\
\hline $3 / 4 / 2001$ & 12.34 \\
\hline $3 / 5 / 2001$ & 16.65 \\
\hline $3 / 6 / 2001$ & 21.14 \\
\hline $3 / 7 / 2001$ & 10.39 \\
\hline $3 / 8 / 2001$ & 21.66 \\
\hline $3 / 9 / 2001$ & 30.53 \\
\hline $3 / 10 / 2001$ & 13.5 \\
\hline $3 / 11 / 2001$ & 21.28 \\
\hline $3 / 16 / 2001$ & 15.94 \\
\hline $3 / 17 / 2001$ & 9.28 \\
\hline $3 / 18 / 2001$ & 13.35 \\
\hline $3 / 19 / 2001$ & 16.76 \\
\hline $3 / 20 / 2001$ & 5.44 \\
\hline $3 / 21 / 2001$ & 6.78 \\
\hline $3 / 22 / 2001$ & 7.9 \\
\hline $3 / 23 / 2001$ & 11.8 \\
\hline $3 / 24 / 2001$ & 18.53 \\
\hline $3 / 25 / 2001$ & 21.22 \\
\hline $3 / 26 / 2001$ & 13.25 \\
\hline $3 / 27 / 2001$ & 27.91 \\
\hline $3 / 28 / 2001$ & 20.79 \\
\hline $3 / 29 / 2001$ & 15.69 \\
\hline $3 / 30 / 2001$ & 11.79 \\
\hline $3 / 31 / 2001$ & 11.02 \\
\hline $4 / 1 / 2001$ & 20.87 \\
\hline $4 / 2 / 2001$ & 11.12 \\
\hline $4 / 3 / 2001$ & 15.58 \\
\hline $4 / 4 / 2001$ & 17.18 \\
\hline $4 / 5 / 2001$ & 26.23 \\
\hline $4 / 6 / 2001$ & 21.57 \\
\hline $4 / 7 / 2001$ & 21.15 \\
\hline $4 / 8 / 2001$ & 22.45 \\
\hline $4 / 9 / 2001$ & 21.22 \\
\hline $4 / 10 / 2001$ & 28.26 \\
\hline $4 / 11 / 2001$ & \\
\hline & 27.18 \\
\hline
\end{tabular}

\begin{tabular}{|c|c|}
\hline Date & TEOM_PM10 \\
\hline $4 / 12 / 2001$ & 20.59 \\
\hline $4 / 13 / 2001$ & 23.37 \\
\hline $4 / 14 / 2001$ & 17.73 \\
\hline $4 / 15 / 2001$ & 24.99 \\
\hline $4 / 16 / 2001$ & 17.95 \\
\hline $4 / 17 / 2001$ & 24.74 \\
\hline $4 / 18 / 2001$ & 21.32 \\
\hline $4 / 19 / 2001$ & 60.45 \\
\hline $4 / 20 / 2001$ & 47.72 \\
\hline $5 / 10 / 2001$ & 25.41 \\
\hline $5 / 11 / 2001$ & 25.55 \\
\hline $5 / 12 / 2001$ & 25.39 \\
\hline $5 / 13 / 2001$ & 25.03 \\
\hline $5 / 14 / 2001$ & 33.29 \\
\hline $5 / 15 / 2001$ & 26.47 \\
\hline $5 / 16 / 2001$ & 39.27 \\
\hline $5 / 17 / 2001$ & 46.58 \\
\hline $5 / 18 / 2001$ & 35.83 \\
\hline $5 / 19 / 2001$ & 27.71 \\
\hline $5 / 20 / 2001$ & 24.68 \\
\hline $5 / 21 / 2001$ & 22.54 \\
\hline $5 / 22 / 2001$ & 21.72 \\
\hline $5 / 23 / 2001$ & 13.16 \\
\hline $5 / 24 / 2001$ & 17.68 \\
\hline $5 / 25 / 2001$ & 144.9 \\
\hline $5 / 26 / 2001$ & 14.63 \\
\hline $5 / 27 / 2001$ & 38.28 \\
\hline $5 / 28 / 2001$ & 23.96 \\
\hline $5 / 29 / 2001$ & 17.87 \\
\hline $5 / 30 / 2001$ & 9.53 \\
\hline $5 / 31 / 2001$ & 21.95 \\
\hline $6 / 1 / 2001$ & 17.41 \\
\hline $6 / 2 / 2001$ & 8.73 \\
\hline $6 / 3 / 2001$ & 18.78 \\
\hline $6 / 4 / 2001$ & 21.94 \\
\hline $6 / 5 / 2001$ & 13.6 \\
\hline $6 / 6 / 2001$ & 12.4 \\
\hline $6 / 7 / 2001$ & 15.1 \\
\hline $6 / 8 / 2001$ & 9.41 \\
\hline $6 / 9 / 2001$ & 14.56 \\
\hline $6 / 10 / 2001$ & 9.97 \\
\hline $6 / 11 / 2001$ & 15.49 \\
\hline $6 / 12 / 2001$ & 10.89 \\
\hline $6 / 13 / 2001$ & 11.96 \\
\hline $6 / 14 / 2001$ & 23.61 \\
\hline $7 / 5 / 2001$ & 9.62 \\
\hline $7 / 6 / 2001$ & 21 \\
\hline $7 / 7 / 2001$ & 18.3 \\
\hline $7 / 8 / 2001$ & 24.49 \\
\hline $7 / 9 / 2001$ & 24.59 \\
\hline & \\
\hline
\end{tabular}


Table A.3. (contd)

\begin{tabular}{|c|c|}
\hline Date & TEOM_PM10 \\
\hline $7 / 10 / 2001$ & 15.03 \\
\hline $7 / 11 / 2001$ & 12.12 \\
\hline $7 / 12 / 2001$ & 9.21 \\
\hline $7 / 13 / 2001$ & 17.38 \\
\hline $7 / 14 / 2001$ & 6.33 \\
\hline $7 / 15 / 2001$ & 6.57 \\
\hline $7 / 16 / 2001$ & 6.41 \\
\hline $7 / 17 / 2001$ & 3.32 \\
\hline $7 / 18 / 2001$ & 6.41 \\
\hline $7 / 19 / 2001$ & 7.53 \\
\hline $7 / 20 / 2001$ & 4.33 \\
\hline $7 / 21 / 2001$ & 2.69 \\
\hline $7 / 22 / 2001$ & 5.15 \\
\hline $7 / 23 / 2001$ & 4.94 \\
\hline $7 / 24 / 2001$ & 5.5 \\
\hline $7 / 25 / 2001$ & 26.21 \\
\hline $7 / 26 / 2001$ & 46.58 \\
\hline $7 / 27 / 2001$ & 35.83 \\
\hline $7 / 28 / 2001$ & 27.71 \\
\hline $8 / 3 / 2001$ & 22.54 \\
\hline $8 / 4 / 2001$ & 21.72 \\
\hline $8 / 5 / 2001$ & 13.16 \\
\hline $8 / 6 / 2001$ & 17.68 \\
\hline $8 / 7 / 2001$ & 144.9 \\
\hline $8 / 8 / 2001$ & 14.63 \\
\hline $8 / 9 / 2001$ & 38.28 \\
\hline $8 / 10 / 2001$ & 23.96 \\
\hline $8 / 11 / 2001$ & 17.87 \\
\hline $8 / 12 / 2001$ & 9.53 \\
\hline $8 / 13 / 2001$ & 21.95 \\
\hline $8 / 23 / 2001$ & 8.8 \\
\hline $8 / 24 / 2001$ & 18.86 \\
\hline $8 / 25 / 2001$ & 19.01 \\
\hline $9 / 5 / 2001$ & 12.08 \\
\hline $9 / 6 / 2001$ & 12.83 \\
\hline $9 / 7 / 2001$ & 15.15 \\
\hline $9 / 8 / 2001$ & 9.25 \\
\hline $9 / 9 / 2001$ & 14.72 \\
\hline $9 / 10 / 2001$ & 10.89 \\
\hline $9 / 11 / 2001$ & 14.21 \\
\hline $9 / 12 / 2001$ & 10.75 \\
\hline $10 / 20 / 2001$ & 10.2 \\
\hline $10 / 21 / 2001$ & 15.62 \\
\hline $10 / 22 / 2001$ & 5.69 \\
\hline $10 / 23 / 2001$ & 5.02 \\
\hline $10 / 24 / 2001$ & 5.48 \\
\hline $10 / 25 / 2001$ & 2.49 \\
\hline $10 / 26 / 2001$ & 7.37 \\
\hline $10 / 27 / 2001$ & 1.69 \\
\hline $10 / 28 / 2001$ & 7.3 \\
\hline & \\
\hline
\end{tabular}

\begin{tabular}{|l|c|}
\hline \multicolumn{1}{|c|}{ Date } & TEOM_PM10 \\
\hline $10 / 29 / 2001$ & 6.56 \\
\hline $10 / 30 / 2001$ & 13.26 \\
\hline $10 / 31 / 2001$ & 15 \\
\hline $11 / 1 / 2001$ & 14.31 \\
\hline $11 / 2 / 2001$ & 8.82 \\
\hline $12 / 24 / 2001$ & -5.01 \\
\hline $12 / 25 / 2001$ & -0.55 \\
\hline $12 / 26 / 2001$ & 1.15 \\
\hline $12 / 27 / 2001$ & -0.84 \\
\hline $12 / 28 / 2001$ & 0.28 \\
\hline $12 / 29 / 2001$ & 2.45 \\
\hline $12 / 30 / 2001$ & -0.08 \\
\hline $12 / 31 / 2001$ & 0.19 \\
\hline $1 / 1 / 2002$ & 3.81 \\
\hline $1 / 2 / 2002$ & 1.54 \\
\hline $1 / 3 / 2002$ & 1.28 \\
\hline $1 / 4 / 2002$ & 1.81 \\
\hline $1 / 5 / 2002$ & 1.74 \\
\hline $1 / 6 / 2002$ & -0.49 \\
\hline $1 / 7 / 2002$ & 1.59 \\
\hline $1 / 8 / 2002$ & 0.34 \\
\hline $1 / 9 / 2002$ & 2.43 \\
\hline $1 / 10 / 2002$ & 0.66 \\
\hline $1 / 11 / 2002$ & -1.14 \\
\hline $1 / 12 / 2002$ & 0.71 \\
\hline $1 / 13 / 2002$ & -0.85 \\
\hline $1 / 14 / 2002$ & 2.71 \\
\hline $1 / 15 / 2002$ & 0.88 \\
\hline $1 / 16 / 2002$ & 0.67 \\
\hline $1 / 17 / 2002$ & 1.92 \\
\hline $1 / 18 / 2002$ & 6.27 \\
\hline $1 / 19 / 2002$ & 2.51 \\
\hline $1 / 20 / 2002$ & 2.02 \\
\hline $1 / 21 / 2002$ & 4.79 \\
\hline $1 / 22 / 2002$ & 0.64 \\
\hline $1 / 23 / 2002$ & 1.66 \\
\hline $1 / 24 / 2002$ & 1.3 \\
\hline $1 / 25 / 2002$ & 2.55 \\
\hline $1 / 26 / 2002$ & 1.26 \\
\hline $1 / 27 / 2002$ & 2.1 \\
\hline $1 / 28 / 2002$ & 2.44 \\
\hline $2 / 2 / 2002$ & -37.71 \\
\hline $2 / 3 / 2002$ & 20.82 \\
\hline $2 / 4 / 2002$ & 12.35 \\
\hline $2 / 5 / 2002$ & 18.64 \\
\hline $2 / 6 / 2002$ & 15.1 \\
\hline $2 / 7 / 2002$ & 5.8 \\
\hline $2 / 8 / 2002$ & 11.76 \\
\hline $2 / 9 / 2002$ & 19.31 \\
\hline $2 / 10 / 2002$ & 9.42 \\
\hline & \\
\hline
\end{tabular}

\begin{tabular}{|l|c|}
\hline \multicolumn{1}{|c|}{ Date } & TEOM_PM10 \\
\hline $2 / 1 / 2002$ & 9.4 \\
\hline $2 / 12 / 2002$ & 14.55 \\
\hline $2 / 13 / 2002$ & 26.01 \\
\hline $2 / 14 / 2002$ & 34.64 \\
\hline $2 / 15 / 2002$ & 18.91 \\
\hline $2 / 16 / 2002$ & 27.67 \\
\hline $2 / 17 / 2002$ & 18.1 \\
\hline $2 / 18 / 2002$ & 8.2 \\
\hline $2 / 19 / 2002$ & 17.07 \\
\hline $2 / 20 / 2002$ & 17.79 \\
\hline $2 / 21 / 2002$ & 10.54 \\
\hline $2 / 22 / 2002$ & 13.67 \\
\hline $2 / 23 / 2002$ & 19.46 \\
\hline $2 / 24 / 2002$ & 25.51 \\
\hline $2 / 25 / 2002$ & 16.3 \\
\hline $2 / 26 / 2002$ & 18.61 \\
\hline $2 / 27 / 2002$ & 10.44 \\
\hline $2 / 28 / 2002$ & 8.26 \\
\hline $3 / 1 / 2002$ & 19.62 \\
\hline $3 / 2 / 2002$ & 11.92 \\
\hline $3 / 3 / 2002$ & 3.14 \\
\hline $3 / 4 / 2002$ & 9.24 \\
\hline $3 / 5 / 2002$ & 15.11 \\
\hline $3 / 6 / 2002$ & 16.95 \\
\hline $3 / 7 / 2002$ & 7.94 \\
\hline $3 / 8 / 2002$ & 12.38 \\
\hline $3 / 9 / 2002$ & 5.67 \\
\hline $4 / 25 / 2002$ & 22.73 \\
\hline $4 / 26 / 2002$ & 26.72 \\
\hline $4 / 27 / 2002$ & 20.34 \\
\hline $4 / 28 / 2002$ & 21.2 \\
\hline $4 / 29 / 2002$ & 19.25 \\
\hline $4 / 30 / 2002$ & 31.17 \\
\hline $5 / 1 / 2002$ & 20.56 \\
\hline $5 / 2 / 2002$ & 27.75 \\
\hline $5 / 3 / 2002$ & 21.94 \\
\hline $5 / 4 / 2002$ & 40.17 \\
\hline $5 / 5 / 2002$ & 16.62 \\
\hline $5 / 6 / 2002$ & 20.83 \\
\hline $5 / 7 / 2002$ & 15.07 \\
\hline $5 / 8 / 2002$ & 45.29 \\
\hline $5 / 9 / 2002$ & 37.98 \\
\hline $5 / 10 / 2002$ & 48.88 \\
\hline $5 / 11 / 2002$ & 17.99 \\
\hline $5 / 12 / 2002$ & 11.02 \\
\hline $5 / 13 / 2002$ & 22.12 \\
\hline $5 / 14 / 2002$ & 7.95 \\
\hline $5 / 15 / 2002$ & 29.33 \\
\hline $5 / 16 / 2002$ & 29.42 \\
\hline $5 / 17 / 2002$ & 18.39 \\
\hline & \\
\hline
\end{tabular}


Table A.3. (contd)

\begin{tabular}{|c|c|}
\hline Date & TEOM_PM10 \\
\hline $5 / 18 / 2002$ & 6.48 \\
\hline $5 / 19 / 2002$ & 9.08 \\
\hline $5 / 20 / 2002$ & 14.43 \\
\hline $5 / 21 / 2002$ & 16.56 \\
\hline $5 / 22 / 2002$ & 22.55 \\
\hline $5 / 23 / 2002$ & 21.57 \\
\hline $5 / 24 / 2002$ & 16.8 \\
\hline $5 / 25 / 2002$ & 22.22 \\
\hline $5 / 26 / 2002$ & 14.29 \\
\hline $5 / 27 / 2002$ & 15.73 \\
\hline $5 / 28 / 2002$ & 19.56 \\
\hline $5 / 29 / 2002$ & 20.08 \\
\hline $5 / 30 / 2002$ & 13.03 \\
\hline $9 / 26 / 2002$ & 11.46 \\
\hline $9 / 27 / 2002$ & 16.34 \\
\hline $9 / 28 / 2002$ & 15.74 \\
\hline
\end{tabular}

\begin{tabular}{|c|c|}
\hline Date & TEOM_PM10 \\
\hline $9 / 29 / 2002$ & 12.44 \\
\hline $9 / 30 / 2002$ & 17.19 \\
\hline $10 / 1 / 2002$ & 12.91 \\
\hline $10 / 2 / 2002$ & 13.21 \\
\hline $10 / 3 / 2002$ & 16.52 \\
\hline $10 / 4 / 2002$ & 19.42 \\
\hline $10 / 5 / 2002$ & 15.1 \\
\hline $10 / 6 / 2002$ & 15.95 \\
\hline $10 / 7 / 2002$ & 24.22 \\
\hline $10 / 8 / 2002$ & 22.77 \\
\hline $10 / 9 / 2002$ & 19.7 \\
\hline $10 / 10 / 2002$ & 13.71 \\
\hline $10 / 11 / 2002$ & 5.52 \\
\hline $10 / 12 / 2002$ & 15.08 \\
\hline $10 / 13 / 2002$ & 11.77 \\
\hline $10 / 14 / 2002$ & 14.13 \\
\hline
\end{tabular}

\begin{tabular}{|c|c|}
\hline Date & TEOM_PM10 \\
\hline $10 / 15 / 2002$ & 10.22 \\
\hline $10 / 16 / 2002$ & 5.95 \\
\hline $10 / 17 / 2002$ & 13.07 \\
\hline $10 / 18 / 2002$ & 12.8 \\
\hline $10 / 19 / 2002$ & 21.62 \\
\hline $10 / 20 / 2002$ & 12.74 \\
\hline $10 / 21 / 2002$ & 21.28 \\
\hline $10 / 22 / 2002$ & 16.35 \\
\hline $10 / 23 / 2002$ & 14.55 \\
\hline $10 / 24 / 2002$ & 14.55 \\
\hline $10 / 25 / 2002$ & 23.08 \\
\hline $10 / 26 / 2002$ & 16.78 \\
\hline $10 / 27 / 2002$ & 17.45 \\
\hline $10 / 28 / 2002$ & 18.84 \\
\hline $10 / 29 / 2002$ & 15.02 \\
\hline $10 / 30 / 2002$ & 10.09 \\
\hline
\end{tabular}




\section{Distribution}

No. of

Copies

OFFSITE

5 Tressa Rutland

Environmental and Natural Resources Division

Department of Public Works

Fort Stewart, GA 31313
No. of

Copies

ONSITE

12 Pacific Northwest National Laboratory

B. C. Barfuss

K2-21

M. A. Chamness

K6-85

C. J. Driver (3)

K2-21

R. R. Kirkham (5)

K9-33

Hanford Technical Library (2) 